\title{
Sildenafil protects against pulmonary hypertension induced by hypoxia in neonatal rats via activation of PPAR $\gamma$-mediated downregulation of TRPC
}

\author{
WANJIE HUANG ${ }^{1}$, NA LIU $^{1}$, XIN TONG $^{1}$ and YANNA DU ${ }^{2}$ \\ ${ }^{1}$ Department of Pediatrics, Shengjing Hospital of China Medical University, Shenyang, Liaoning 110004; \\ ${ }^{2}$ Department of Pediatrics, The First Affiliated Hospital of Zhengzhou University, Zhengzhou, Henan 450000, P.R. China
}

Received March 4, 2021; Accepted November 4, 2021

DOI: $10.3892 /$ ijmm.2021.5074

\begin{abstract}
Persistent pulmonary hypertension of the newborn (PPHN) is a common pulmonary vascular disease during the neonatal period, and it is associated with a high clinical mortality rate and a poor prognosis. At present, the treatment of PPHN is based mainly on inhaled nitric oxide (iNO), high-frequency ventilation, and pulmonary vasodilators. Sildenafil has gradually begun to be used in recent years for the treatment of PPHN and has exhibited some success; however, its detailed mechanism of action requires further elucidation. An animal model of neonatal pulmonary hypertension (neonatal rats, $48 \mathrm{~h}$ after birth, $10 \% \mathrm{O}_{2}$, 14 days) as well as a cell model [human pulmonary artery smooth muscle cells (PASMCs), 4\% $\mathrm{O}_{2}, 60 \mathrm{~h}$ ] were established. The effects of sildenafil on pulmonary hypertension in neonatal rats were evaluated by hematoxylin and eosin staining, immunofluorescence analysis, western blotting and PCR, and the changes in peroxisome proliferator-activated receptor $\gamma(\operatorname{PPAR} \gamma)$, transient receptor potential canonical (TRPC)1, TRPC6 and Ki67 expression levels were detected under hypoxic conditions. The results revealed that sildenafil reversed the increases in the right ventricular mean pressure and right ventricular hypertrophy index induced by hypoxia, and attenuated pulmonary arterial remodeling as well as
\end{abstract}

Correspondence to: Dr Wanjie Huang, Department of Pediatrics, Shengjing Hospital of China Medical University, 36 Sanhao Street, Shenyang, Liaoning 110004, P.R. China

E-mail: 59682101@qq.com

Abbreviations: PPHN, persistent pulmonary hypertension of the newborn; PPAR $\gamma$, peroxisome proliferator-activated receptor $\gamma$; TRPC, transient receptor potential canonical; iNO, inhaled nitric oxide; PASMC, pulmonary artery smooth muscle cell; IHC, immunohistochemistry; IF, immunofluorescence; RV mean pressure, right ventricular mean pressure; RVHI, right ventricular hypertrophy index

Key words: sildenafil, pulmonary hypertension, $\operatorname{PPAR} \gamma$, transient receptor potential canonical channels, neonatal rats
PASMC proliferation. The inhibitory effects of sildenafil on TRPC expression and PASMC proliferation were attenuated by GW9662 and PPAR $\gamma$ small interfering RNA. In conclusion, sildenafil protects against hypoxia-induced pulmonary hypertension and right ventricular hypertrophy in neonatal rats by upregulating PPAR $\gamma$ expression and downregulating TRPC1 and TRPC6 expression.

\section{Introduction}

Persistent pulmonary hypertension of the newborn (PPHN) is the most common severe pulmonary vascular disease in the neonatal intensive care unit (NICU), and mortality rates in US centers range from $4-33 \%$ (1). The pathological changes include an increase in the pulmonary artery contraction response and excessive remodeling of the distal pulmonary arterioles (including thickening of the vessel walls and obstruction of small blood vessels), particularly proliferation of pulmonary artery smooth muscle cells (PASMCs) (2-4). Based on the above changes, the current treatment of PPHN utilizes a comprehensive strategy, including inhaled nitric oxide (iNO), mechanical ventilation to improve oxygenation and drugs inducing dilation of the pulmonary vasculature, such as prostaglandins (iloprost and treprostinil), endothelin receptor antagonists (bosentan and ambrisentan) and phosphodiesterase 5 inhibitors (such as sildenafil and tadalafil) (5-8).

Sildenafil is currently the most widely used pulmonary vasoactive drug. Clinical studies have confirmed that sildenafil results in vasodilation comparable to that caused by iNO in patients with pulmonary hypertension, and that it is beneficial for patients with idiopathic pulmonary hypertension and other primary subtypes. However, the detailed mechanism of action requires further elucidation (1,9-11).

Sildenafil is a selective and potent phosphodiesterase 5 inhibitor that can relax distal pulmonary arterioles through the classic iNO/cGMP/PKG pathway to achieve pulmonary hypertension $(10,12-14)$.

Peroxisome proliferator-activated receptor $\gamma(\operatorname{PPAR} \gamma)$, a member of one of three related nuclear receptor superfamilies (PPAR $\alpha, \operatorname{PPAR} \gamma$ and PPAR $\beta / \delta$ ), is a ligand-activated transcription factor (15) that regulates lung and alveolar development, regulates pulmonary vascular tone and decreases PASMC 
proliferation, thus inhibiting vascular remodeling (16). PPAR $\gamma$ also mediates the protective effects of sildenafil against acute kidney injury (AKI) (17) induced by ischemia-reperfusion in rats and Adriamycin-induced nephropathy (14).

The transient receptor potential canonical (TRPC) gene family is known to be the molecular basis of store-operated calcium channels (SOCCs) and receptor-operated calcium channels (ROCCs) in PASMCs. Previous studies have shown that chronic hypoxia selectively upregulates the expression of TRPC1 and TRPC6 in PASMCs (18). In addition, PPAR $\gamma$ can inhibit the expression of store-operated calcium entry (SOCE) channels and TRPCs in PASMCs by inhibiting caveolin-1 (19). These results indicate that PPAR $\gamma$ acts as an upstream signal of TRPCs and affects the proliferation and migration of PASMCs through TRPCs.

In the preliminary work of the present study, a PPHN rat model was established via hypoxia exposure and indomethacin treatment. PPAR $\gamma$ expression was decreased, whereas TRPC1 and TRPC6 expression were significantly increased in the model (20), suggesting that activation of PPAR $\gamma$ expression and reductions in TRPC1 and TRPC6 expression may play roles in dilating pulmonary vessels and improving pulmonary vascular remodeling.

Based on the establishment of this model of pulmonary hypertension in neonatal rats, conventional techniques, such as hematoxylin and eosin (H\&E) staining, immunofluorescence (IF), western blotting, and PCR were used to explore the possible mechanisms of action of sildenafil in addition to the classical pathway.

\section{Materials and methods}

Animals. This study was approved by the Ethics Committee of Shengjing Hospital of China Medical University (Shenyang, China; approval no. 2019PS026K). All experimental procedures and protocols were performed in accordance with the guidelines for the care and use of experimental animals. A total of 39 newborn specific pathogen-free (SPF) Sprague-Dawley (SD) rats (male: female, 1:1; body weight 5-7 g) were provided by the SPF-level laboratory of the Animal Experimental Center of Shengjing Hospital affiliated with China Medical University. A total of 15 newborn rats were used for the preliminary experiments, and 24 newborn rats were used for the formal experiments. All the animals were fed with sufficient food and water, and kept in a natural environment (12-h light/dark cycles; temperature range: $25-27^{\circ} \mathrm{C}$; and humidity range, $50-70 \%$ ).

Reagents and materials. Sildenafil citrate (Selleck Chemicals; cat. no. S1431), GW9662 (Abcam; cat. no. ab141125), PPAR $\gamma$ antibody (Abcam; cat. no. ab19481), TRPC1 antibody (Sigma-Aldrich; Merck KGaA; cat. no. T8276), TRPC6 antibody (ProteinTech Group, Inc.; cat. no. 18236-1-AP), Ki67 antibody (Cell Signaling Technology, Inc.; cat. no. 9129), $\beta$-actin antibody (Abcam; cat. no. ab8226), donkey anti-mouse IgG H\&L (Alexa Fluor ${ }^{\circledR} 488$ ) (Abcam; cat. no. ab150105), anti-rabbit IgG H\&L (Alexa Fluor ${ }^{\circledR}$ 594) (Abcam; cat. no. ab150076), a small animal ventilator (ALC-V8D; Shanghai Alcott Biotech, Co.), and an electrophysiological recorder (BL-420F; Biosignal Acquisition and Analysis System,
Chengdu Taimeng Software, Co., Ltd.) were used in the present study.

Model preparation. According to our previously established method $(21,22)$, newborn rats were fed by maternal rats after full-term delivery and maintained under normal atmospheric conditions for $48 \mathrm{~h}$. In the pre-experiment, 15 neonatal rats were randomly divided into 5 groups according to their body weight: i) Normoxic control group [fraction of inspired oxygen $\left(\mathrm{FiO}_{2}\right)$ 0.21 \pm 0.05 ; temperature $25-27^{\circ} \mathrm{C}$; humidity $50-70 \%$; $\mathrm{n}=3]$; ii) hypoxia group $\left(\mathrm{FiO}_{2} 0.1 \pm 0.05\right.$; temperature $25-27^{\circ} \mathrm{C}$; humidity $50-70 \% ; \mathrm{n}=3)$; iii) hypoxia $+5 \mathrm{mg} / \mathrm{kg} /$ day sildenafil group $\left(\mathrm{FiO}_{2} 0.1 \pm 0.05\right.$; temperature $25-27^{\circ} \mathrm{C}$; humidity $50-70 \%$; sildenafil $5 \mathrm{mg} / \mathrm{kg} /$ day; $=3) ;$ iv)hypoxia $+10 \mathrm{mg} / \mathrm{kg} /$ day sildenafil group $\left(\mathrm{FiO}_{2} 0.1 \pm 0.05\right.$; temperature $25-27^{\circ} \mathrm{C}$; humidity $50-70 \%$; sildenafil $10 \mathrm{mg} / \mathrm{kg} / \mathrm{day} ; \mathrm{n}=3)$; and $\mathrm{v}$ ) hypoxia $+25 \mathrm{mg} / \mathrm{kg} /$ day sildenafil group $\left(\mathrm{FiO}_{2} 0.1 \pm 0.05\right.$; temperature $25-27^{\circ} \mathrm{C}$; humidity $50-70 \%$; sildenafil $25 \mathrm{mg} / \mathrm{kg} / \mathrm{day} ; \mathrm{n}=3$ ). The oxygen concentration and air humidity were continuously monitored. In the formal experiments, 24 neonatal rats were randomly divided into 3 groups according to their body weight: i) Control group, in which the rats were kept in a normal-air environment $\left(\mathrm{FiO}_{2}\right.$ $0.21 \pm 0.05$; temperature $25-27^{\circ} \mathrm{C}$; humidity $50-70 \%$; $n=8$ ); ii) PPHN model group, in which the rats were placed in a hypoxic glass box for 14 days $\left(\mathrm{FiO}_{2} 0.1 \pm 0.05\right.$; temperature $25-27^{\circ} \mathrm{C}$; humidity $50-70 \%$; $\mathrm{n}=8$ ); and iii) sildenafil treatment group, in which the rats were subjected to conditions equivalent to those of the PPHN group and were placed in the hypoxic glass box on the first day of intragastric administration $(25 \mathrm{mg} / \mathrm{kg} /$ day sildenafil was administered by gavage with a no. 8 gavage needle; the first dose was administered immediately prior to placement in the hypoxic glass box; $n=8)(23)$. The mother rats were exchanged between the experimental group/sildenafil treatment group and the control group every $24 \mathrm{~h}$ to avoid a decrease in feeding ability due to hypoxia. The litter was replaced when the mother was replaced, and the sildenafil group was administered the drug treatment. The operation was completed within $15 \mathrm{~min}$.

Hemodynamic evaluations. After 14 days, mice were anesthetized with sodium pentobarbital $(50 \mathrm{mg} / \mathrm{kg}$, intraperitoneal injection). The mice were fixed, intubated and connected to a small animal ventilator. The heart was exposed through a sternotomy, and the trocar tip connected to the multichannel physiological recorder was inserted into the right ventricle (RV) to monitor the RV pressure (an indirect response to pulmonary artery pressure).

Specimen collection. Following hemodynamic evaluations, the animals were euthanized by an intraperitoneal injection of $50 \mathrm{mg} / \mathrm{kg}$ body weight pentobarbital, followed by exsanguination. The heart and lungs were rapidly removed en bloc from the thoracic cavity. The RV and left ventricle + ventricular septum $(\mathrm{LV}+\mathrm{S})$ were carefully separated under the microscope and weighed separately. The right ventricular hypertrophy index (RVHI) was calculated as the RV weight/LV+S weight. The lower lobe of the right lung was fixed in $4 \%$ paraformaldehyde for 48-72 $\mathrm{h}$ at room temperature, embedded in paraffin, and $4.5 \mu \mathrm{m}$ sections were prepared for H\&E staining, immunohistochemistry (IHC) and IF staining. 
$H \& E$ staining. The paraffin blocks were cut into $4-\mu \mathrm{m}$-thick sections. The sections were stained with hematoxylin for $5 \mathrm{~min}$ at room temperature and then washed with running water for $30 \mathrm{~min}$. The slices were next stained with eosin for $1 \mathrm{~min}$ at room temperature and then washed with water.

IF staining to observe the localization and expression of $\alpha$-SMA, PPAR $\gamma$, TRPC1, TRPC6 and Ki67. Paraffin sections of lung tissue were dewaxed in a gradient of alcohol solutions and xylene. After the samples were immersed in PBS and placed in Tris-EDTA repair solution for microwave antigen retrieval, they were washed three times with PBS, soaked in PBS containing $0.3 \%$ Triton $\mathrm{X}$ for $10 \mathrm{~min}$, and blocked with goat serum for $40 \mathrm{~min}$ at room temperature. Primary antibodies $(\alpha$-SMA, 1:40; PPAR $\gamma, 1: 2.5$; TRPC1, 1:50; TRPC6, 1:20; and Ki67, 1:80) were added, and the sections were incubated overnight at $4^{\circ} \mathrm{C}$. The following day (after 14-16 h), the samples were rewarmed at room temperature for $30 \mathrm{~min}$, washed three times with PBS, and incubated with a fluorescent secondary antibody mixture [Alexa Fluor 488 (green) donkey anti-mouse IgG or Alexa Fluor 594 (red) anti-rabbit IgG; both at 1:100]. The samples were incubated for $4 \mathrm{~h}$ at room temperature in the dark, washed three times with PBS, stained with DAPI for nuclear staining, washed again three times and imaged with a confocal microscope (magnification, x40; scale bar, $50 \mu \mathrm{m}$; NIKON C1, Nikon Corporation).

Cell IF. The cells were fixed with $4 \%$ paraformaldehyde for 20 min, and then $0.3 \%$ Triton X-100 was used for cell permeabilization; all aforementioned steps were performed at room temperature. The sections were washed with PBS three times, immunostained with primary antibodies ( $\alpha$-SMA, 1:100) and incubated in a wet chamber overnight at $4^{\circ} \mathrm{C}$. The sections were stained with the corresponding secondary antibody (1:100) and incubated at room temperature for $30 \mathrm{~min}$. The nucleus was stained for $5 \mathrm{~min}$ with DAPI at room temperature.

Real-time PCR detection of PPAR $\gamma, T R P C 1$ and TRPC6 gene expression in lung tissue. A total of 8 samples from each group were obtained, and total RNA was extracted using TRIzol ${ }^{\circledR}$ reagent (Thermo Fisher Scientific, Inc.) according to the manufacturer's protocol. The RNA purity and concentration were determined based on the optical density (OD) 260/280 nM ratio. The mRNA was reverse-transcribed into cDNA using a PrimeScript RT Reagent kit (Takara Bio, Inc.). A SYBR Green PCR kit (Takara Bio, Inc.) was used according to the manufacturer's instructions with an Applied Biosystems 7500 Real-Time PCR system (Applied Biosystems 7500; Thermo Fisher Scientific, Inc.), and the final volume of the reaction mixture for PCR was $20 \mu 1$.

The PCR thermocycling conditions were: $95^{\circ} \mathrm{C}$ for $30 \mathrm{sec}$; followed by 40 cycles of $95^{\circ} \mathrm{C}$ for $5 \mathrm{sec}$ and $60^{\circ} \mathrm{C}$ for $34 \mathrm{sec}$. The gene expression levels were calculated using the $2^{-\Delta \Delta \mathrm{Cq}}$ method (24). $\beta$-actin was used as an internal control. The primer sequences are listed in Table I.

Western blot detection of PPAR, TRPC1 and TRPC6 protein levels in lung tissue. Total protein was extracted from lung tissue; the protein concentration was determined using a BCA assay; $30 \mu \mathrm{g}$ protein samples were separated on an $8 \%$ SDS-gel
Table I. Gene-specific primer sequences.

\begin{tabular}{lc}
\hline Gene & \multicolumn{1}{c}{ Sequence, 5'-3' } \\
\hline $\begin{array}{l}\text { PPAR } \gamma \\
\text { Forward } \\
\text { Reverse } \\
\text { TRPC } 1\end{array}$ & ACCACAGTTGATTTCTCCAG \\
Forward & TGTTGTAGAGCTGGGTCTTT \\
Reverse & \\
TRPC6 & AGCCTCTTGACAAACGAGGA \\
Forward & ACCTGACATCTGTCCGAACC \\
Reverse & \\
Ki67 & TACTGGTGTGCTCCTTGCAG \\
Forward & GAGCTTGGTGCCTTCAAATC \\
Reverse & \\
$\beta$-actin & CCTGCCCGACCCTACAAAAT \\
Forward & TCCGCCGTCTTAAGGTAGGA \\
Reverse & \\
\hline
\end{tabular}

PPAR $\gamma$, peroxisome proliferator-activated receptor $\gamma$; TRPC, transient receptor potential canonical.

using SDS-PAGE and transferred to PVDF membranes; the membranes were blocked using 5\% skimmed milk at room temperature in TBST (10\% Tween-20) for $2 \mathrm{~h}$ to block nonspecific binding. The membranes were then incubated overnight at $4^{\circ} \mathrm{C}$ with primary antibodies against PPAR $\gamma(1: 400)$, TRPC1 (1:200), TRPC6 (1:500) and $\beta$-actin $(1: 2,000)$. After the membranes were washed three times with TBST, they were incubated with a goat anti-rabbit secondary antibody or a goat anti-mouse secondary antibody for $2 \mathrm{~h}$ at room temperature. After another wash, signals were visualized using enhanced chemiluminescence reagent, and an imaging system was used for imaging. ImageJ version 1.8.0 (National Institutes of Health) was used to analyze the density of the protein bands and to normalize the protein levels to those of $\beta$-actin; the values are expressed in arbitrary units.

Culture of human PASMCs (HPASMCs). The HPASMCs were derived from ScienCell primary cells (purchased from Guangzhou Huatuo Biotechnology Co., Ltd.). Cells were cultured in high-glucose DMEM (Hyclone) containing $10 \%$ FBS (CLARK), 1\% penicillin and streptomycin (Biological Industries). When the cells grew to $80-90 \%$ confluence, they were subcultured every 3-5 days, and cells at passage 4-8 were used for follow-up experiments. To simulate the pathological process of hypoxic pulmonary hypertension in vitro, HPASMCs were cultured under normal and hypoxic conditions. The conventional culture conditions were $37^{\circ} \mathrm{C}$, $5 \% \mathrm{CO}_{2}$ and $21 \% \mathrm{O}_{2}$, and the hypoxic conditions were $37^{\circ} \mathrm{C}$, $5 \% \mathrm{CO}_{2}$ and $4 \% \mathrm{O}_{2}$.

The cells were divided into three groups: i) the normoxic control group $\left(21 \% \mathrm{O}_{2}, 60 \mathrm{~h}, \mathrm{n}=3\right)$; ii) the hypoxic group $\left(4 \% \mathrm{O}_{2}\right.$, $60 \mathrm{~h}, \mathrm{n}=3)$ and iii) the hypoxia + sildenafil group $\left(4 \% \mathrm{O}_{2}, 60 \mathrm{~h}\right.$, $n=3$ ), to investigate the role of sildenafil on HPASMCs under hypoxic conditions. 
Then HPASMCs were exposed to hypoxia and treated with sildenafil and GW9662 (PPAR- $\gamma$ antagonist). The cells were divided into four groups: i) the hypoxic control group $(n=3)$, ii) the hypoxia + sildenafil group $(n=3)$, iii) the hypoxia + GW9662 group (n=3) and iv) the hypoxia + sildenafil + GW9662 group $(n=3)$.

Small interfering (si)RNA transfection. Hanheng Biotechnology (Shanghai) Co., Ltd., siRNA targeting the PPAR $\gamma$ gene and negative control siRNA. Cells were seeded at $2 \times 10^{5}$ cells/well in a 6 -well plate and transfected the following day with $3 \mu \mathrm{l}$ of the indicated siRNAs $(20 \mu \mathrm{M})$ or controls using a Lipofectamine ${ }^{\mathrm{TM}} 2000$ transfection kit (Invitrogen; Thermo Fisher Scientific, Inc.) according to the manufacturer's instructions. After culturing at $37^{\circ} \mathrm{C}$ for $48 \mathrm{~h}$, the cells were counted and lysed for RNA and protein extraction.

Three siRNA sequences (siR-PP1, siR-PP2 and siR-PP3) targeting the PPAR $\gamma$ gene were designed. The sequences of the siRNAs are listed in Table II. The cells were divided into four groups: si-NC, siR-PP1, siR-PP2 and siR-PP3.

The effects of sildenafil and PPAR $\gamma$ siRNA in cultured HPASMCs under hypoxic conditions were further investigated. The cells were divided into four groups: i) The hypoxic control group $\left(60 \mathrm{~h}, 4 \% \mathrm{O}_{2}\right)$, ii) the hypoxia + sildenafil group $\left(60 \mathrm{~h}, 4 \% \mathrm{O}_{2}\right)$, iii) the hypoxia + siR-PP1 group $\left(60 \mathrm{~h}, 4 \% \mathrm{O}_{2}\right)$, and iv) the hypoxia + sildenafil + siR-PP1 group.

Statistical analysis. The data are expressed as the mean \pm the standard error of the mean. Statistical analysis was performed using SPSS version 23 (IBM Corp.). Differences between groups were compared using an one-way ANOVA followed by a post hoc LSD test. $\mathrm{P}<0.05$ was considered to indicate a statistically significant difference.

\section{Results}

Sildenafil reverses the increases in the $R V$ mean pressure and $R V H I$ induced by hypoxia and attenuates pulmonary arterial remodeling. At $48 \mathrm{~h}$ after birth, neonatal rats were randomly divided into 5 groups for a pre-experiment (Fig. 1A): i) the normoxic control group $(\mathrm{n}=3)$; ii) the hypoxia group $\left(10 \% \mathrm{O}_{2}\right.$, $\mathrm{n}=3)$; iii) the hypoxia $+5 \mathrm{mg} / \mathrm{kg} /$ day sildenafil group $\left(10 \% \mathrm{O}_{2}\right.$, sildenafil $5 \mathrm{mg} / \mathrm{kg} / \mathrm{day}, \mathrm{n}=3)$, iv) the hypoxia $+10 \mathrm{mg} / \mathrm{kg} / \mathrm{day}$ sildenafil group $\left(10 \% \mathrm{O}_{2}\right.$, sildenafil $\left.10 \mathrm{mg} / \mathrm{kg} / \mathrm{day}, \mathrm{n}=3\right)$, and v) the hypoxia $+25 \mathrm{mg} / \mathrm{kg} /$ day sildenafil group $\left(10 \% \mathrm{O}_{2}\right.$, sildenafil $25 \mathrm{mg} / \mathrm{kg} / \mathrm{day}, \mathrm{n}=3$ ). The $\mathrm{RV}$ mean pressure and RVHI were measured after 14 days. The results showed that $25 \mathrm{mg} / \mathrm{kg} /$ day sildenafil significantly attenuated the increase in RV pressure and RVHI caused by hypoxia-induced pulmonary hypertension in newborn rats, so $25 \mathrm{mg} / \mathrm{kg} /$ day was selected for subsequent tests.

In the formal experiment, neonatal rats were randomly divided into 3 groups: i) the normoxic control group $(\mathrm{n}=8)$, ii) the hypoxia group $\left(10 \% \mathrm{O}_{2}, \mathrm{n}=8\right)$, and iii) the hypoxia + sildenafil group $\left(10 \% \mathrm{O}_{2}\right.$, sildenafil $25 \mathrm{mg} / \mathrm{kg} / \mathrm{day}$, $\mathrm{n}=8$ ). A total of 14 days later, the RV pressure and RVHI were measured, and lung tissue samples were collected. As shown in Fig. 1B, the RV mean pressure measured in the hypoxia group was $19.63 \pm 1.35 \mathrm{mmHg}$, which was significantly higher than that in the normoxic control group $(10.13 \pm 0.58 \mathrm{mmHg}$,
Table II. Sequences of the siRNAs targeting the PPAR $\gamma$ genes used in this study.

\begin{tabular}{lc}
\hline siRNA & \multicolumn{1}{c}{ Sequence } \\
\hline $\begin{array}{l}\text { siR-PP1 } \\
\text { Sense } \\
\text { Antisense }\end{array}$ & GGUUGCAGAUUACAAGUAUdTdT \\
siR-PP2 & AUACUUGUAAUCUGCAACCdTdT \\
Sense & CAAGAGUACCAAAGUGCAAdTdT \\
Antisense & UUGCACUUUGGUACUCUUGdTdT \\
siR-PP3 & \\
Sense & GGAGAACAAUCAGAUUGAAdTdT \\
Antisense & UUCAAUCUGAUUGUUCUCCdTdT \\
\hline
\end{tabular}

$\operatorname{PPAR} \gamma / \mathrm{PP}$, peroxisome proliferator-activated receptor $\gamma$; siRNA, small interfering RNA.

$\mathrm{P}<0.05)$, and the RVHI measured in the hypoxia group was $58.91 \pm 3.22 \%$, which was significantly higher than that in the normoxic control group $(28.01 \pm 1.48 \%, \mathrm{P}<0.05)$. However, the increases in the RV mean pressure and the RVHI were significantly inhibited by intragastric administration of sildenafil. The data showed that the RV mean pressure and RVHI decreased significantly to $14.93 \pm 0.88 \mathrm{mmHg}(\mathrm{P}<0.05)$ and $46.85 \% \pm 2.18 \%(\mathrm{P}<0.05)$, respectively (Fig. 1B).

With regard to morphology, H\&E staining (Fig. 1C) of lung tissue sections was performed to observe the remodeling of distal pulmonary arterioles. Compared with those in the normoxic control group, the distal pulmonary arteriolar walls (Fig. 1D) in the hypoxia group were significantly thickened and the lumina were narrowed, whereas sildenafil treatment alleviated the hypoxia-induced arterial wall thickening and lumen narrowing.

Sildenafil attenuates hypoxia-induced downregulation of PPAR $\mathrm{r}$ expression and inhibits hypoxia-induced upregulation of TRPC expression in neonatal rats. The protein levels in lung tissue homogenates were detected (Fig. 2A). The results showed a significant decrease in PPAR $\gamma$ protein expression in the hypoxia group. This change was attenuated by sildenafil, similar to the change in the mRNA levels (Fig. 2B). However, the expression levels in lung homogenates may not be representative of the expression levels in distal pulmonary small vessels. Subsequently, double IF staining for $\alpha$-SMA and PPAR $\gamma$ was performed on lung tissue sections to further clarify the localization and expression levels of PPAR $\gamma$ in lung tissue (Fig. 2C). The results of IF double staining showed that the fluorescence of PPAR $\gamma$ colocalized with $\alpha$-SMA was significantly decreased in the hypoxia group. Compared with that in the hypoxia group, the fluorescence of PPAR $\gamma$ was enhanced in the hypoxia + sildenafil group (Fig. 2D). The fluorescence trend of PPAR $\gamma$ was the same as the protein and mRNA expression trends in lung homogenates.

The data showed a marked increase in TRPC1 protein expression in the hypoxia group (Fig. 3A). The change was attenuated by sildenafil, similar to the change in mRNA levels 
A
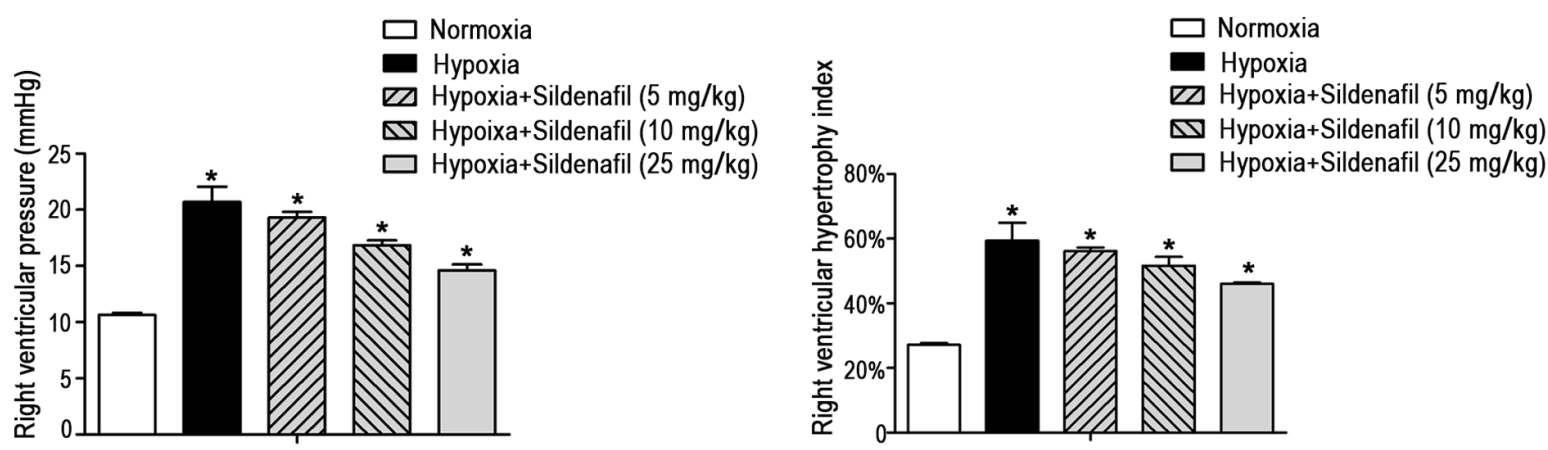

B
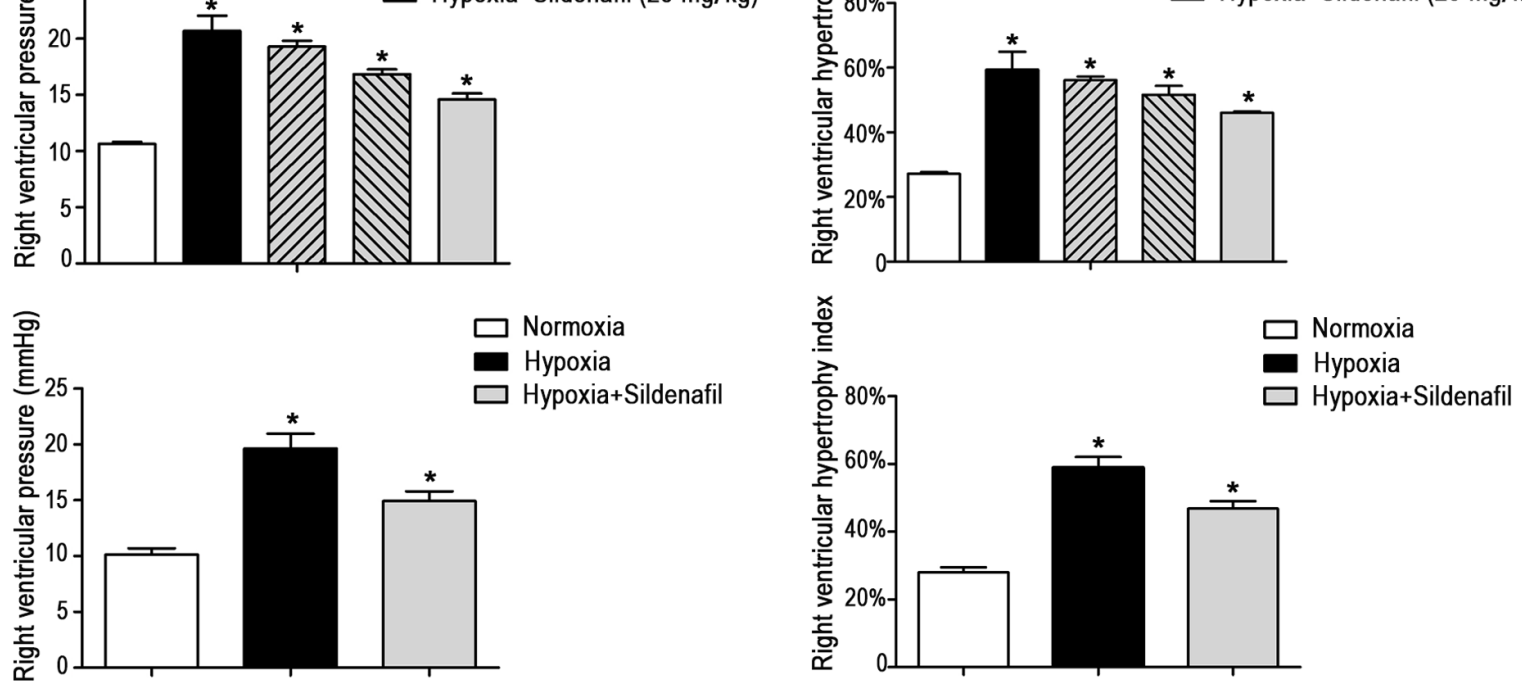

C

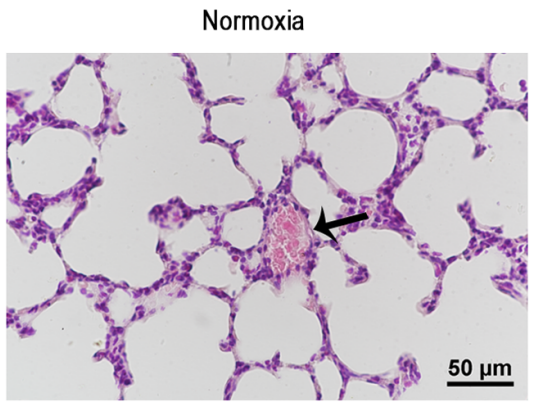

Hypoxia
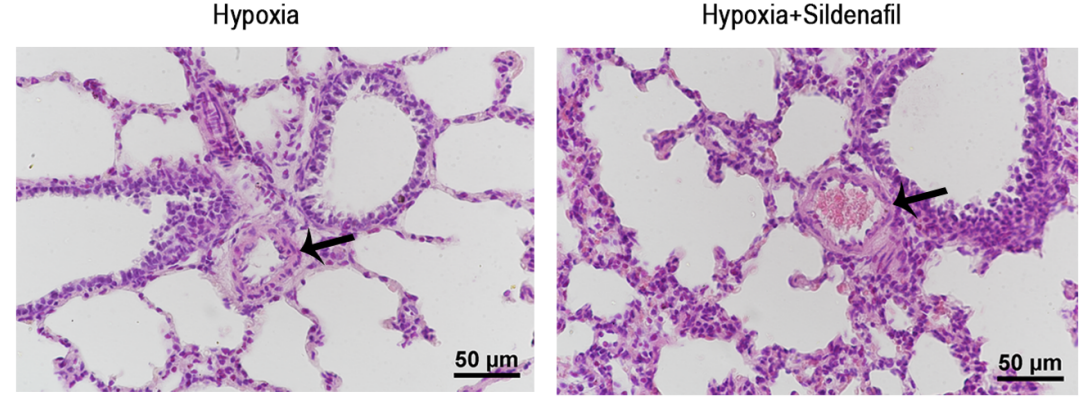

D

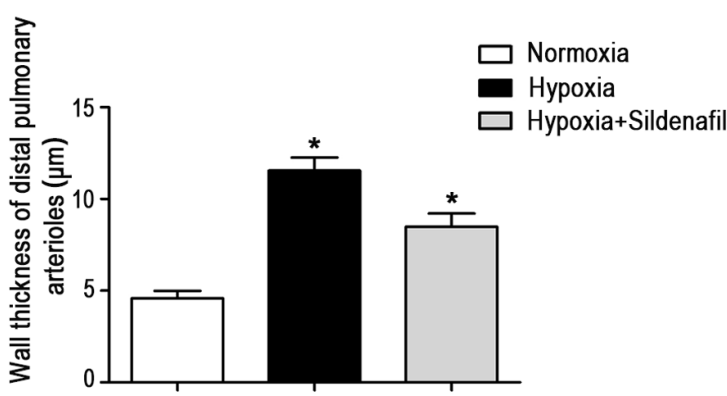

Figure 1. Sildenafil attenuated the increase in the RV mean pressure and RVHI induced by hypoxia and attenuated pulmonary arterial remodeling. (A) Different concentrations of sildenafil attenuated the increase in the RV mean pressure in neonatal rats induced by hypoxia. There were five groups: i) the normoxic control group (14 days), ii) the hypoxia group (14 days, $10 \% \mathrm{O}_{2}$ ), iii) the hypoxia $+5 \mathrm{mg} / \mathrm{kg} / \mathrm{day}$ sildenafil group (14 days, $10 \% \mathrm{O}_{2}, 5 \mathrm{mg} / \mathrm{kg} / \mathrm{days} \mathrm{sildenafil),} \mathrm{iv)} \mathrm{the}$ hypoxia $+10 \mathrm{mg} / \mathrm{kg} /$ day sildenafil group (14 days, $10 \% \mathrm{O}_{2}, 10 \mathrm{mg} / \mathrm{kg} /$ days sildenafil), and v) the hypoxia $+25 \mathrm{mg} / \mathrm{kg} / \mathrm{day}$ sildenafil group (14 day, $10 \%$ O $25 \mathrm{mg} / \mathrm{kg} /$ day sildenafil). Different concentrations of sildenafil attenuated the increase in the RVHI in neonatal rats induced by hypoxia. $\mathrm{n}=3$. (B) Sildenafil attenuated the increase in the RV mean pressure in neonatal rats induced by hypoxia. There were three groups: i) the normoxic control group (14 days), ii) the hypoxia group (14 days, $10 \% \mathrm{O}_{2}$ ), and iii) the hypoxia + sildenafil group (14 days, $10 \% \mathrm{O}_{2}, 25 \mathrm{mg} / \mathrm{kg} /$ day sildenafil). Sildenafil attenuated the increase in the RVHI in neonatal rats induced by hypoxia + sildenafil group. $n=8$. (C) Representative H\&E-stained photomicrographs of the distal pulmonary artery. Sildenafil treatment reduced hypoxia-induced pulmonary arterial wall thickening. The arrows indicate the distal pulmonary arteriolar wall. Magnification, $\mathrm{x} 40$; scale bar, $50 \mu \mathrm{m}$. (D) Quantitative analysis of the wall thickness of the distal pulmonary artery. Data are presented as the mean \pm standard deviation. Sildenafil treatment reduced hypoxia-induced pulmonary arterial wall thickening. $n=8$. " $\mathrm{P}<0.05$ vs. control. RV, right ventricular; RVHI, RV hypertrophy index; H\&E, hematoxylin and eosin.

(Fig. 3B). The fluorescence trend of TRPC1 (Fig. 3C and D) was the same as the protein and mRNA expression trends in lung homogenates.

The data showed a marked increase in TRPC6 protein expression in the hypoxia group (Fig. 4A). The changes were attenuated by sildenafil, similar to the changes in mRNA levels (Fig. 4B) and fluorescence levels (Fig. 4C and D).
Sildenafil attenuates hypoxia-induced downregulation of PPAR $\gamma$ expression and inhibits hypoxia-induced upregulation of TRPC expression and cell proliferation in HPASMCs during prolonged hypoxia. HPASMCs derived from ScienCell primary cells were used for the in vitro experiments. Under normoxic conditions, IF staining of $\alpha$-SMA in HPASMCs showed that green fluorescence was present throughout the 
A

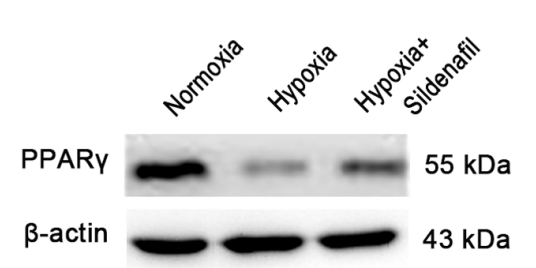

C
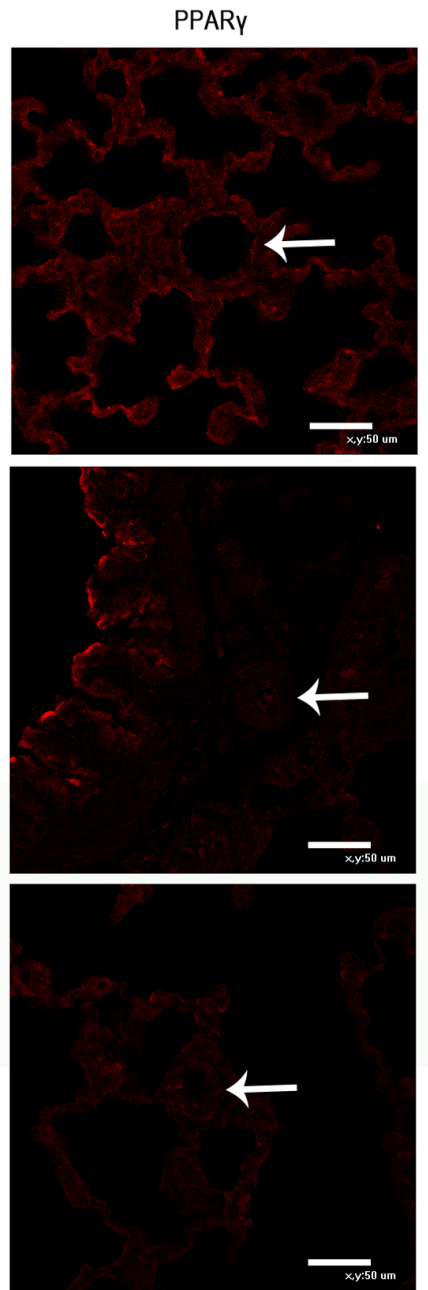

$\mathrm{D} . \underline{\mathscr{B}}$

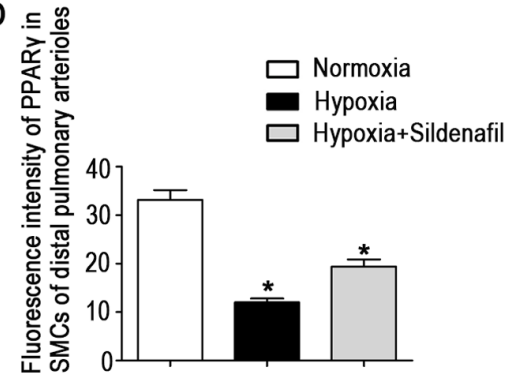

B

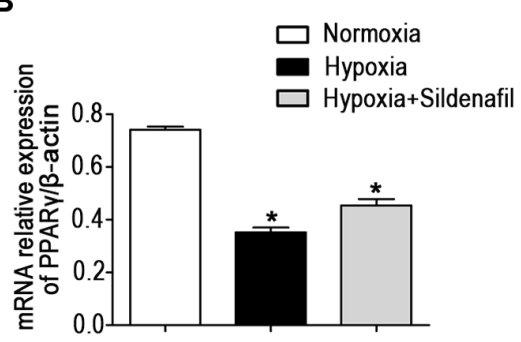

Merged
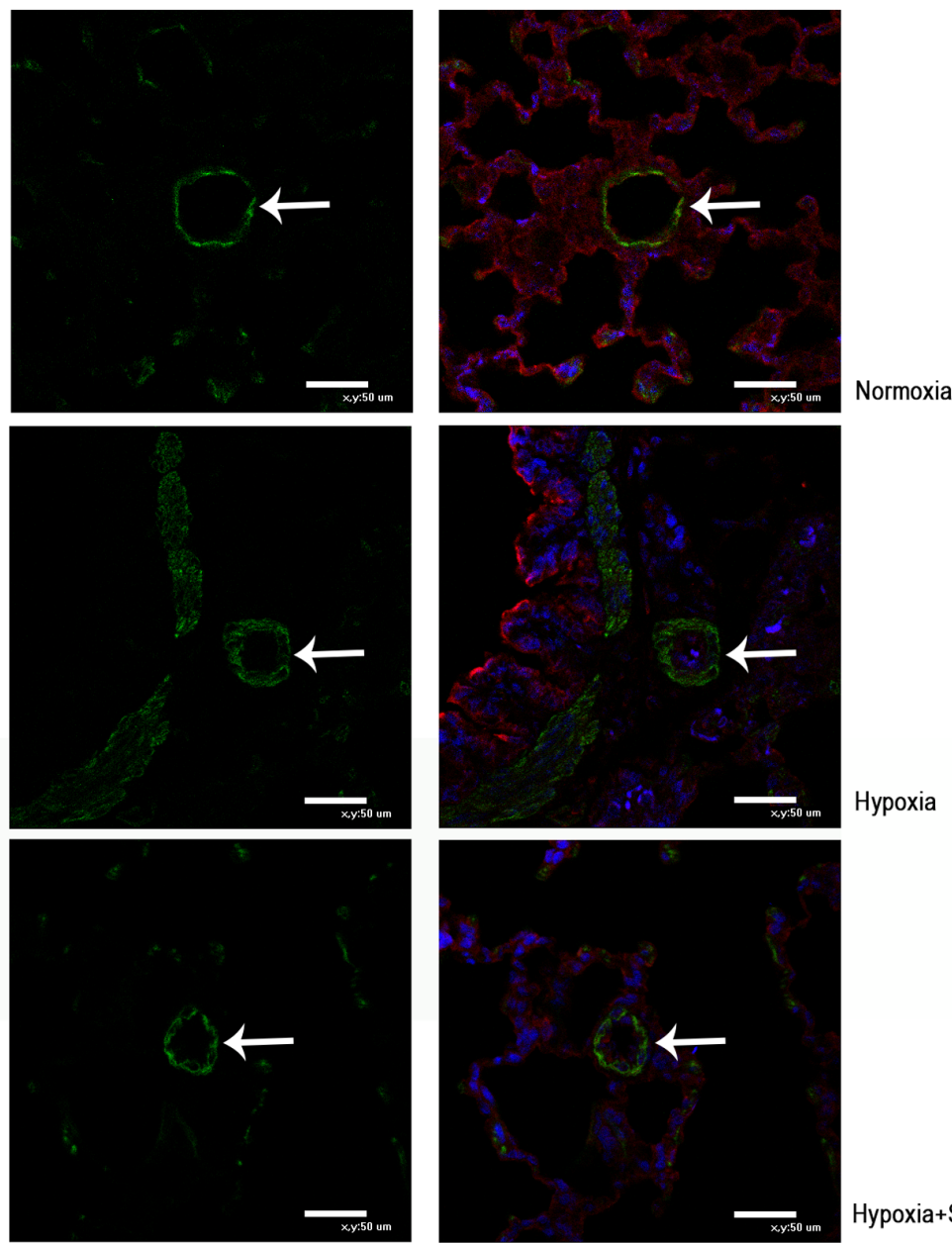

Hypoxia+Sildenafil

Figure 2. Sildenafil attenuated hypoxia-induced downregulation of PPAR $\gamma$ expression in the lung tissues of neonatal rats. (A) Western blot and (B) reverse transcription-quantitative PCR analysis of the sildenafil-mediated attenuation of hypoxia-induced downregulation of PPAR $\gamma$ protein and mRNA expression in the lung tissues of neonatal rats. (C) Double immunofluorescence staining for $\alpha$-SMA (green) and PPAR $\gamma$ (red) in the lung tissue sections. The arrows indicate the distal pulmonary arteriolar wall. Sildenafil inhibited the hypoxia-induced downregulation of PPAR $\gamma$ expression in the lung tissues of neonatal rats. Magnification, $x 40$. Scale bar, $50 \mu \mathrm{m}$. (D) Quantitative analysis of the PPAR $\gamma$ fluorescence intensity in the SMCs of distal pulmonary arterioles. Sildenafil inhibited the hypoxia-induced downregulation of PPAR $\gamma$ expression in the lung tissues of neonatal rats. Data are presented as the mean \pm standard deviation of three repeats. ${ }^{*} \mathrm{P}<0.05$ vs. control group. PPAR $\gamma$, peroxisome proliferator-activated receptor $\gamma$; SMC, smooth muscle cells; SMA, smooth muscle actin.

HPASMCs, and the cell morphology was as described in previous literature (Fig. 5A) $(25,26)$.
The HPASMCs were cultured under normoxic or hypoxic conditions. To determine the optimal concentration of sildenafil, 
A

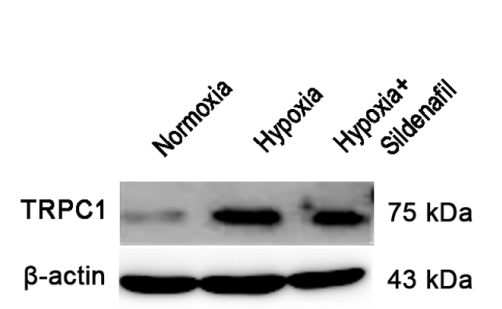

C
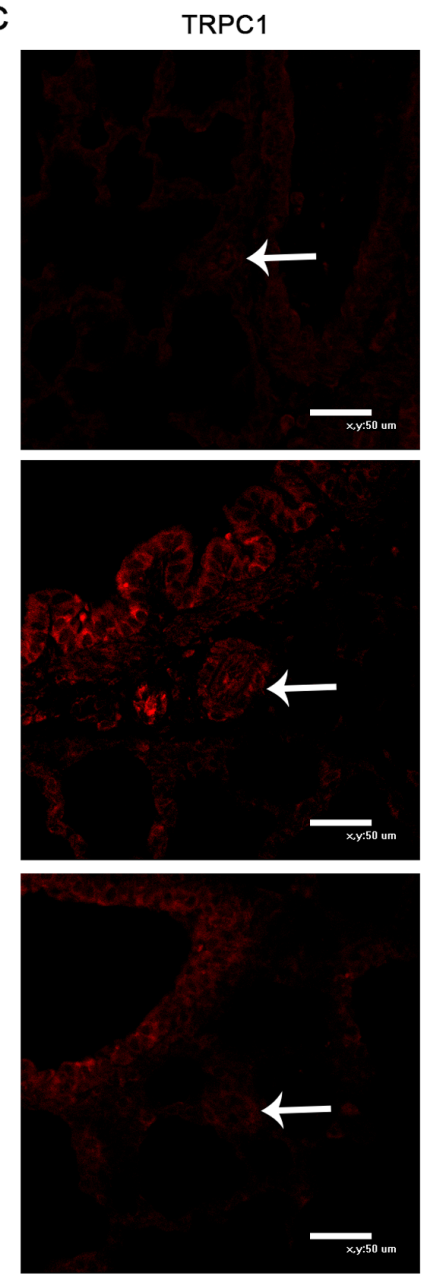

D

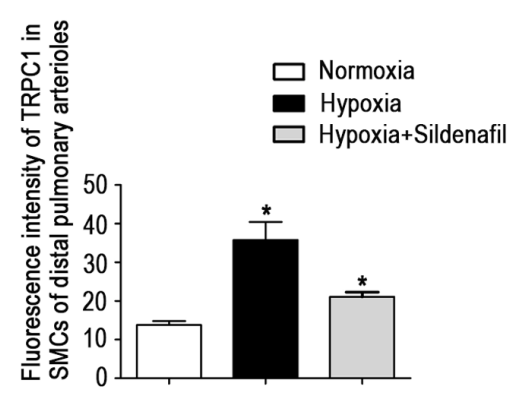

B
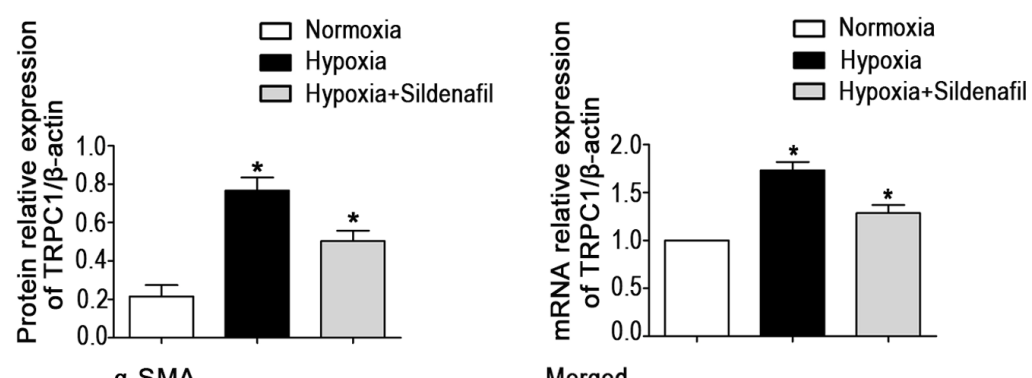

Merged
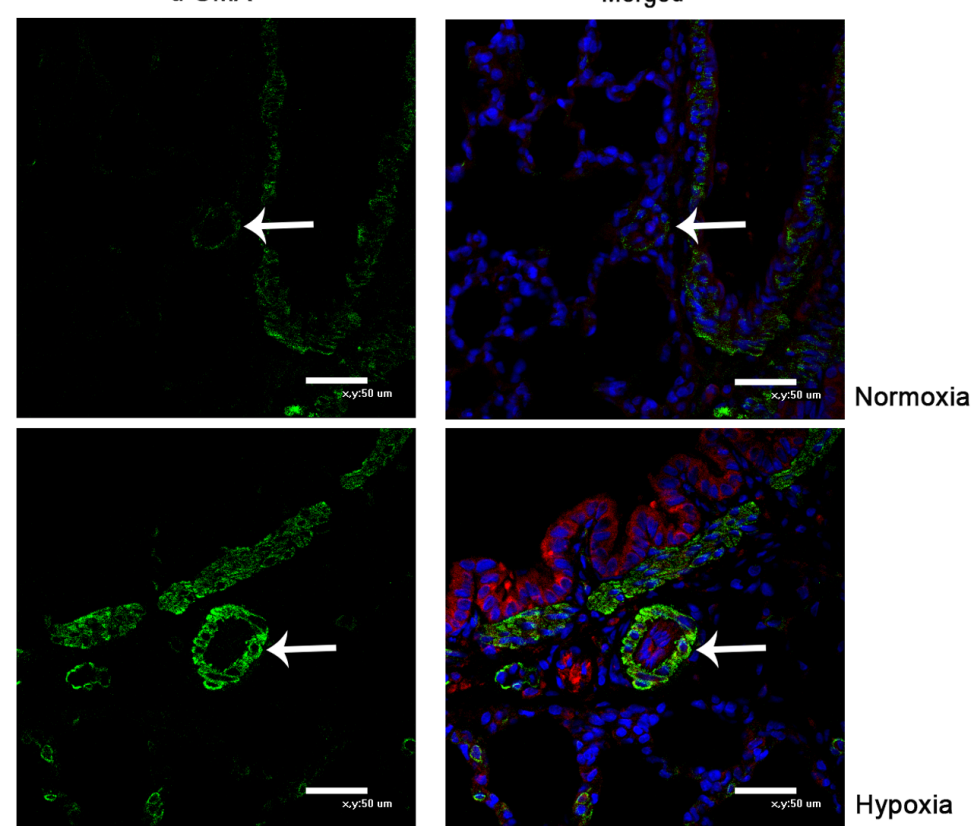

\section{Normoxia}
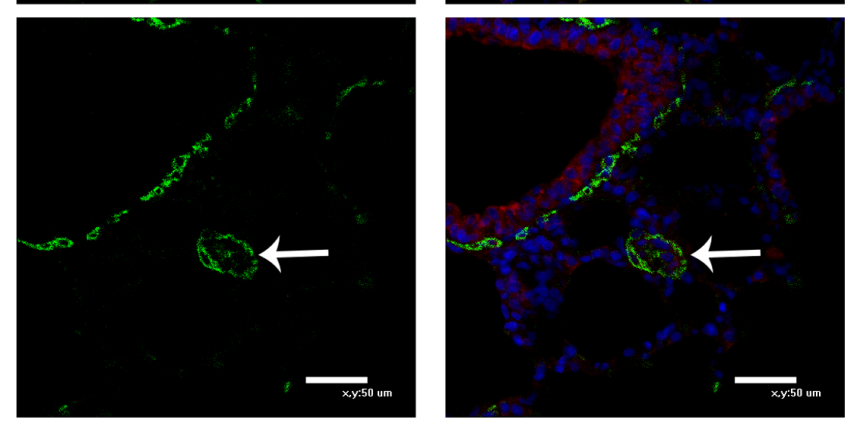

Hypoxia

Hypoxia+Sildenafil

Figure 3. Sildenafil inhibited the hypoxia-induced upregulation of TRPC1 expression in the lungs of neonatal rats. (A) Western blot and (B) reverse transcription-quantitative PCR analysis of the sildenafil-mediated inhibition of hypoxia-induced upregulation of TRPC1 protein and mRNA expression in the lung tissues of neonatal rats. (C) Double immunofluorescence staining for $\alpha$-SMA (green) and TRPC1 (red) in lung tissue sections. The arrows indicate the distal pulmonary arteriolar wall. Sildenafil inhibited the hypoxia-induced upregulation of TRPC1 expression in the lung tissues of neonatal rats. Magnification, $\mathrm{x} 40$. Scale bar, $50 \mu \mathrm{m}$. (D) Quantitative analysis of the TRPC1 fluorescence intensity in the SMCs of distal pulmonary arterioles sildenafil inhibited the hypoxia-induced upregulation of TRPC1 expression in the lung tissues of neonatal rats. Data are presented as the mean \pm standard deviation. "P $<0.05$ vs. control group. TRPC1, transient receptor potential canonical 1; SMC, smooth muscle cells; SMA, smooth muscle actin.

four concentrations of sildenafil, $0,1,10$ and $50 \mathrm{nM}$, were applied to HPASMCs in a hypoxic state. The protein (Fig. 5B) and mRNA (Fig. 5C) expression levels of PPAR $\gamma$ were detected after the cells were cultured for $60 \mathrm{~h}$. The changes in PPAR $\gamma$ 
A

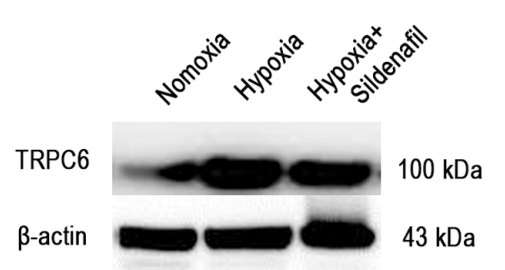

C
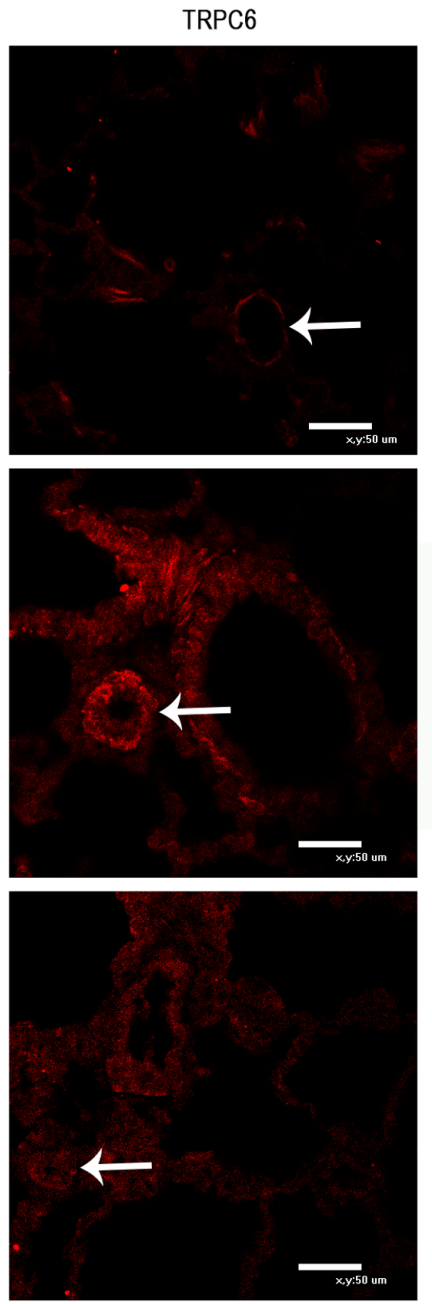

D

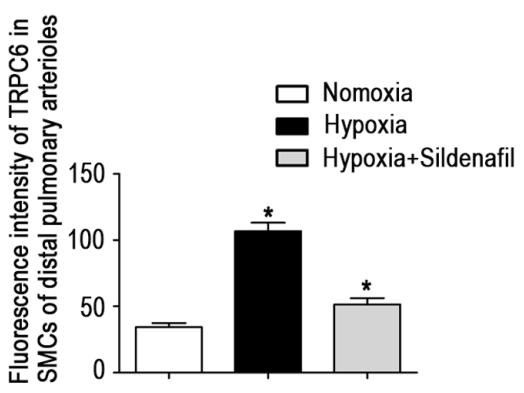

B

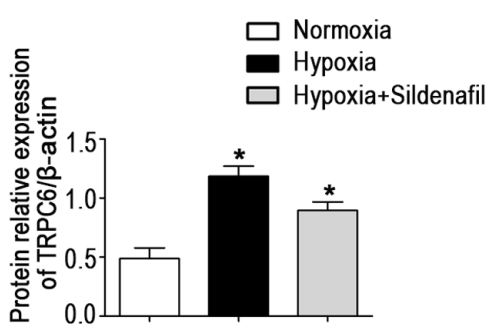

a-SMA
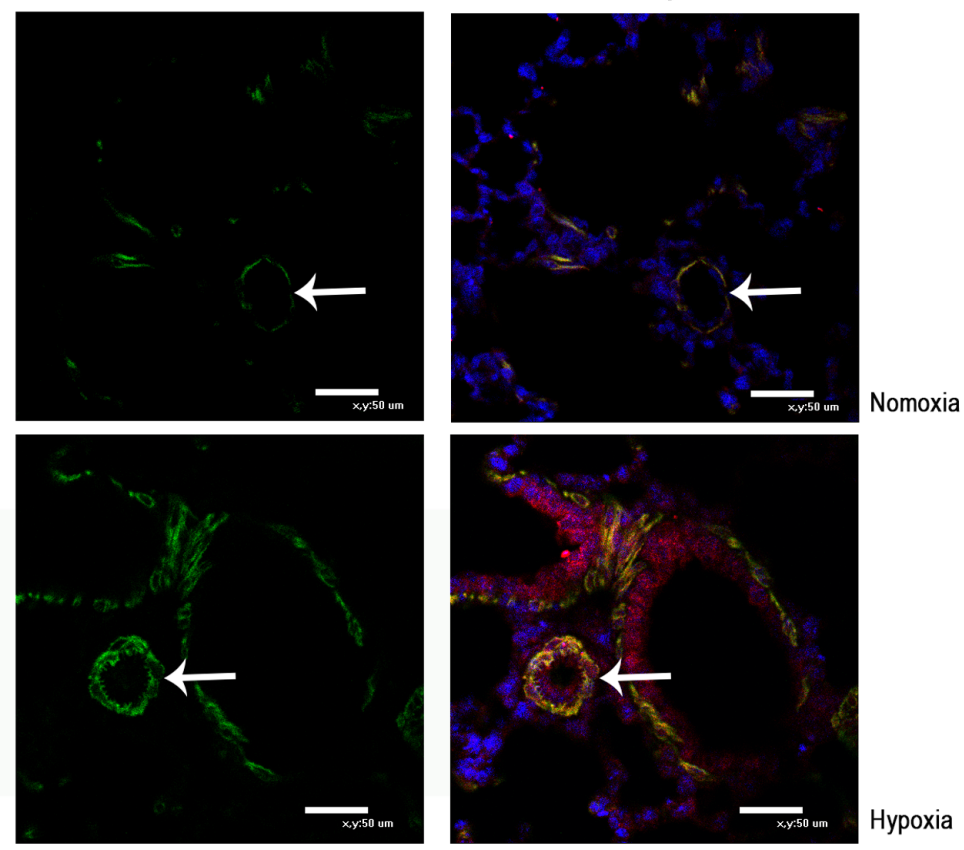

Hypoxia
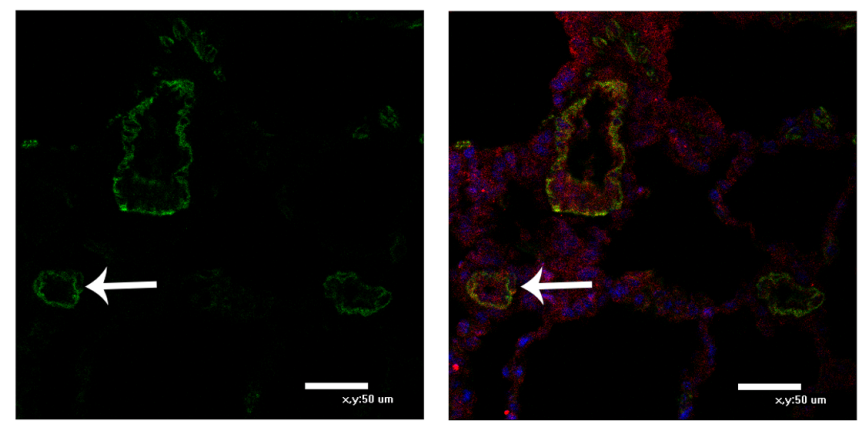

Hypoxia+Sildenafil

Figure 4. Sildenafil inhibited the hypoxia-induced upregulation of TRPC6 expression in the lung tissues of neonatal rats. (A) Western blot and (B) reverse transcription-quantitative PCR analysis of the sildenafil-mediated inhibition of hypoxia-induced upregulation of TRPC6 protein and mRNA expression in the lung tissues of neonatal rats. (C) Double immunofluorescence staining for $\alpha$-SMA (green) and TRPC6 (red) in lung tissue sections. The arrows indicate the distal pulmonary arteriolar wall. Sildenafil inhibited the hypoxia-induced upregulation of TRPC1 expression in the lung tissues of neonatal rats. Magnification, $\mathrm{x} 40$. Scale bar, $50 \mu \mathrm{m}$. (D) Quantitative analysis of the TRPC6 fluorescence intensity in the SMCs of distal pulmonary arterioles sildenafil inhibited the hypoxia-induced upregulation of TRPC6 expression in the lung tissues of neonatal rats. Data are presented as the mean \pm standard deviation. "P $<0.05$ vs. control group. TRPC6, transient receptor potential canonical 6; SMC, smooth muscle cells; SMA, smooth muscle actin.

were not obvious with the $10 \mathrm{nM}$ treatment. Therefore, $10 \mathrm{nM}$ was selected as the sildenafil dose for the follow-up experiment.
The cells were divided into three groups: i) the normoxic control group $\left(21 \% \mathrm{O}_{2}, 60 \mathrm{~h}, \mathrm{n}=3\right)$; ii) the hypoxic group 
A

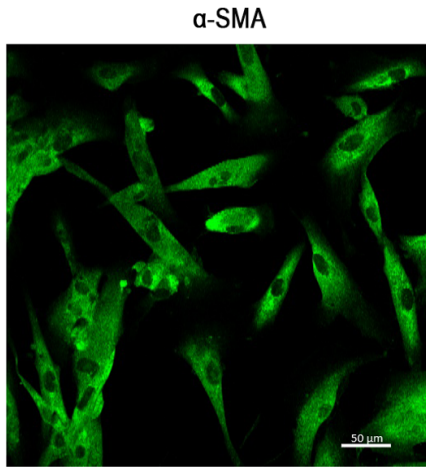

B

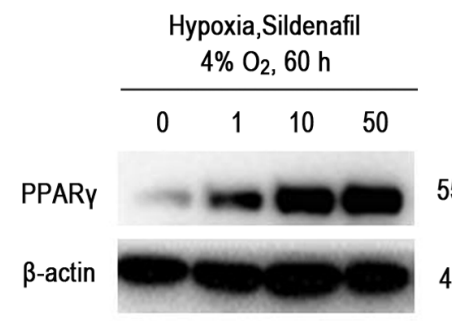

D

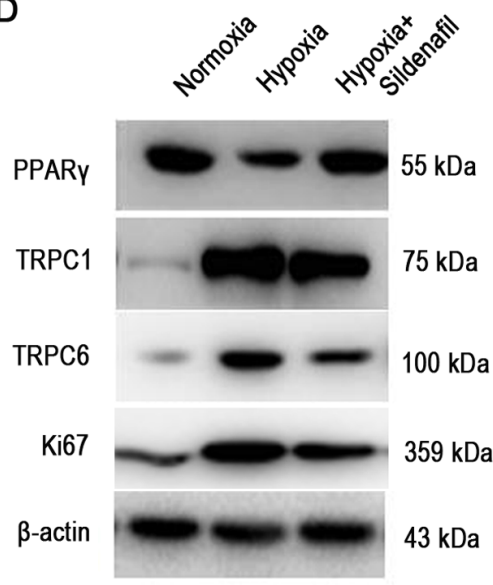

DAPI
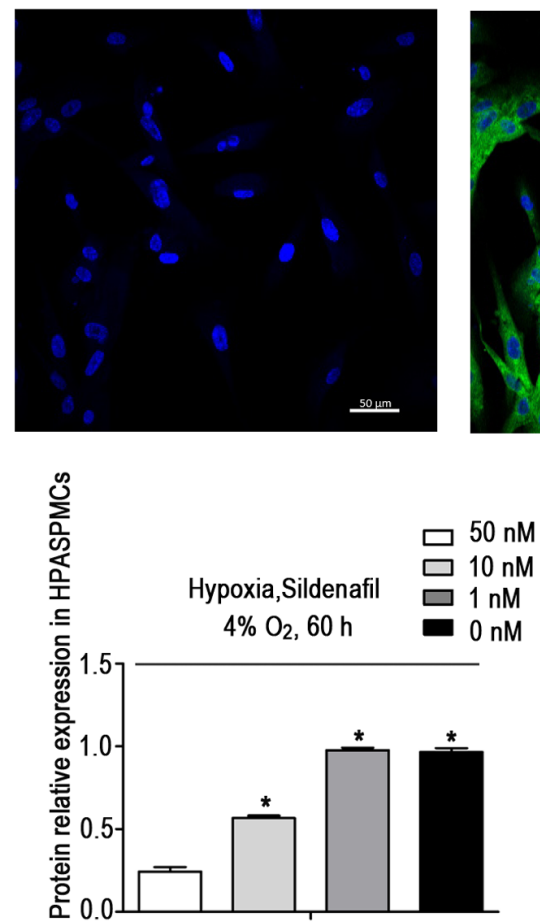

E

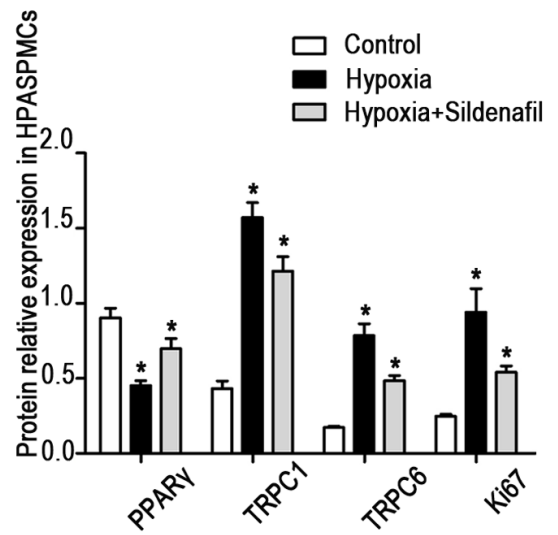

C
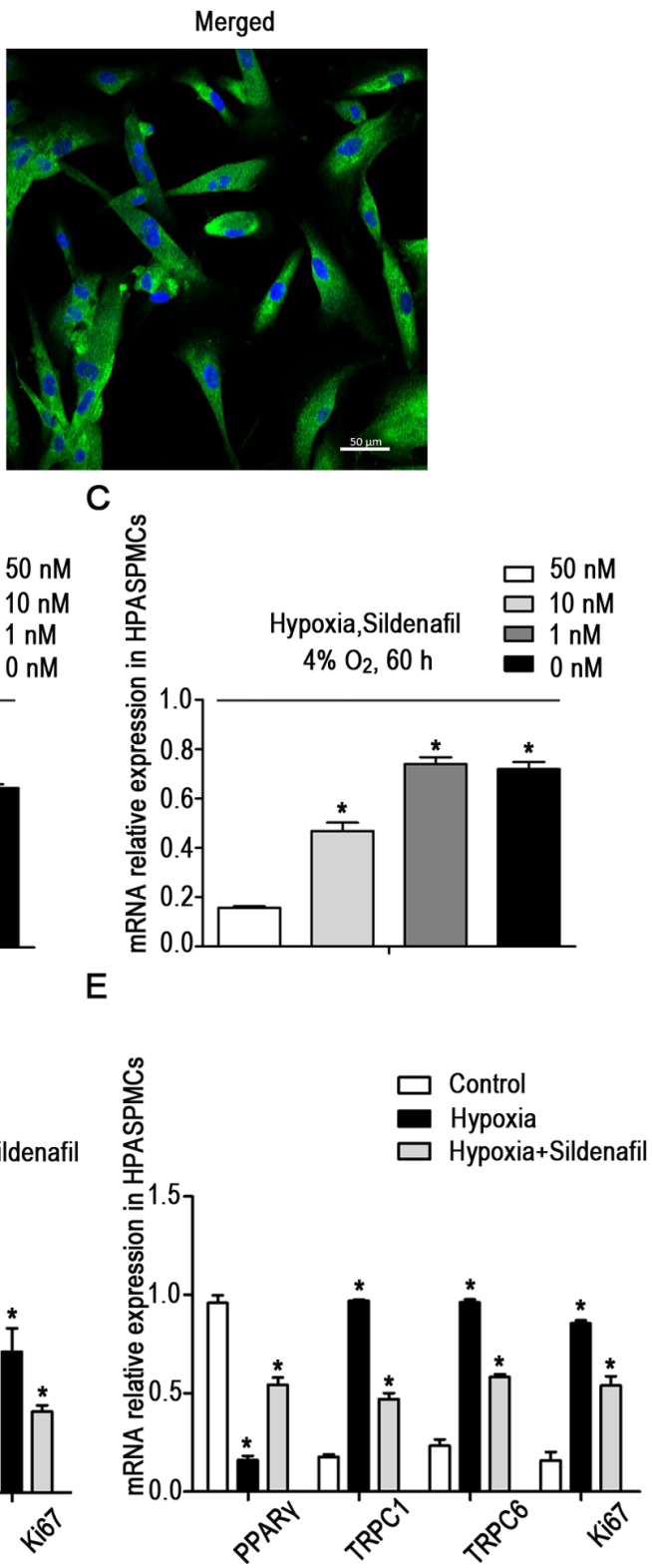

Figure 5. Sildenafil attenuated the hypoxia-induced downregulation of PPAR $\gamma$ expression and inhibited the hypoxia-induced upregulation of TRPC and Ki67 expression in HPASMCs. (A) HPASMCs were identified by immunofluorescence staining for $\alpha$-SMA in cells grown under normoxic conditions. (B) Western blot and (C) RT-qPCR analysis of the increase in PPAR $\gamma$ protein and mRNA expression in HPASMCs induced by different concentrations of sildenafil under hypoxic conditions. Each of the four groups were treated with $0,1,10$ or $50 \mathrm{nM}$ sildenafil. (D) Western blot and (E) RT-qPCR analysis of the sildenafil-mediated attenuation of hypoxia-induced downregulation of PPAR $\gamma$ expression and sildenafil-mediated inhibition of hypoxia-induced upregulation of TRPC and Ki67 expression in HPASMCs. There were three experimental groups: i) The normoxic control group $(60 \mathrm{~h})$, ii) the hypoxia group $\left(60 \mathrm{~h}, 4 \% \mathrm{O}_{2}\right)$, and iii) the hypoxia + sildenafil group $\left(60 \mathrm{~h}, 4 \% \mathrm{O}_{2}, 50 \mathrm{nM}\right.$ sildenafil). Data are presented as the mean \pm standard deviation of three repeats. "P $<0.05$ vs. control. PPAR $\gamma$, peroxisome proliferator-activated receptor $\gamma$; HPASMC, human pulmonary artery smooth muscle cell; SMA, smooth muscle actin; TRPC, transient receptor potential canonical; RT-qPCR, reverse transcription-quantitative PCR.

$\left(4 \% \mathrm{O}_{2}, 60 \mathrm{~h}, \mathrm{n}=3\right)$ and $\left.\mathrm{iii}\right)$ the hypoxia + sildenafil group $\left(4 \% \mathrm{O}_{2}, 60 \mathrm{~h}, \mathrm{n}=3\right)$. The protein (Fig. 5D) and mRNA (Fig. 5E) expression levels of PPAR $\gamma$, TRPC1 and TRPC6 were detected. Compared with the normoxic control cells, HPASMCs exposed to prolonged hypoxia exhibited decreases in PPAR $\gamma$ expression and increases in TRPC1 and TRPC6 expression, and these changes were attenuated by sildenafil.

In the in vitro experiments, the expression of $\mathrm{Ki} 67$ protein (Fig. 5D) and mRNA (Fig. 5E) was detected. The results showed that the expression of Ki67 was significantly increased in the hypoxic group, and that the increase was attenuated by sildenafil.
Sildenafil inhibits hypoxia-induced upregulation of TRPC expression and cell proliferation in HPASMCs by activating PPAR $\gamma$. HPASMCs were treated with GW9662, an inhibitor of PPAR $\gamma$. Three concentrations of GW9662 (0, 1 and $10 \mathrm{nM}$ ) were used during exposure to hypoxia (4\%) for $60 \mathrm{~h}$. The expression of PPAR $\gamma$ was detected and found to be significantly inhibited by a concentration of $10 \mathrm{nM}$ (Fig. 6A and $\mathrm{B})$.

HPASMCs were exposed to hypoxia and treated with sildenafil and GW9662. The cells were divided into four groups: i) the hypoxic control group $(n=3)$, ii) the hypoxia + sildenafil group $(n=3)$, iii) the hypoxia + GW9662 group $(n=3)$ and 
A

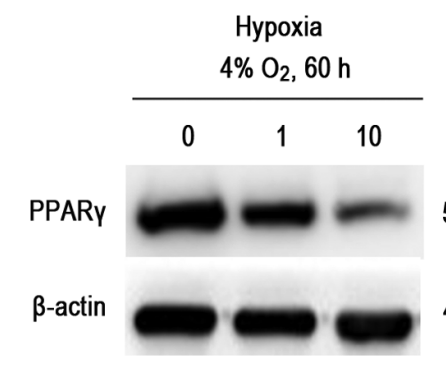

$55 \mathrm{kDa}$

$43 \mathrm{kDa}$

C
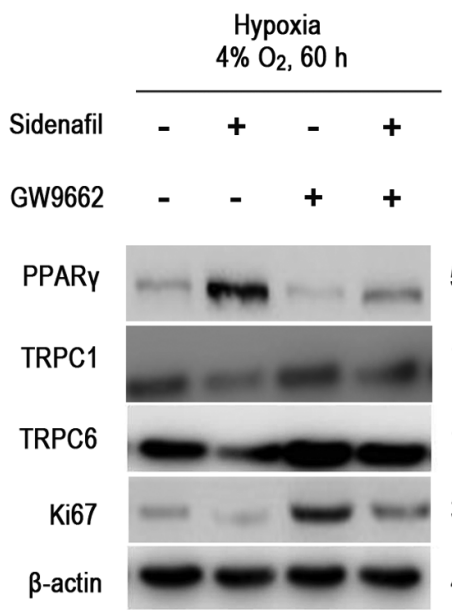

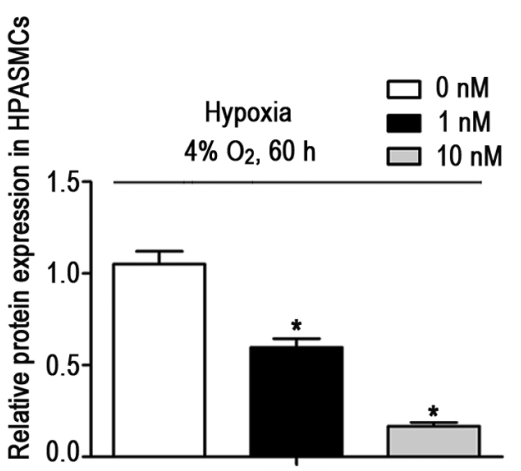

B
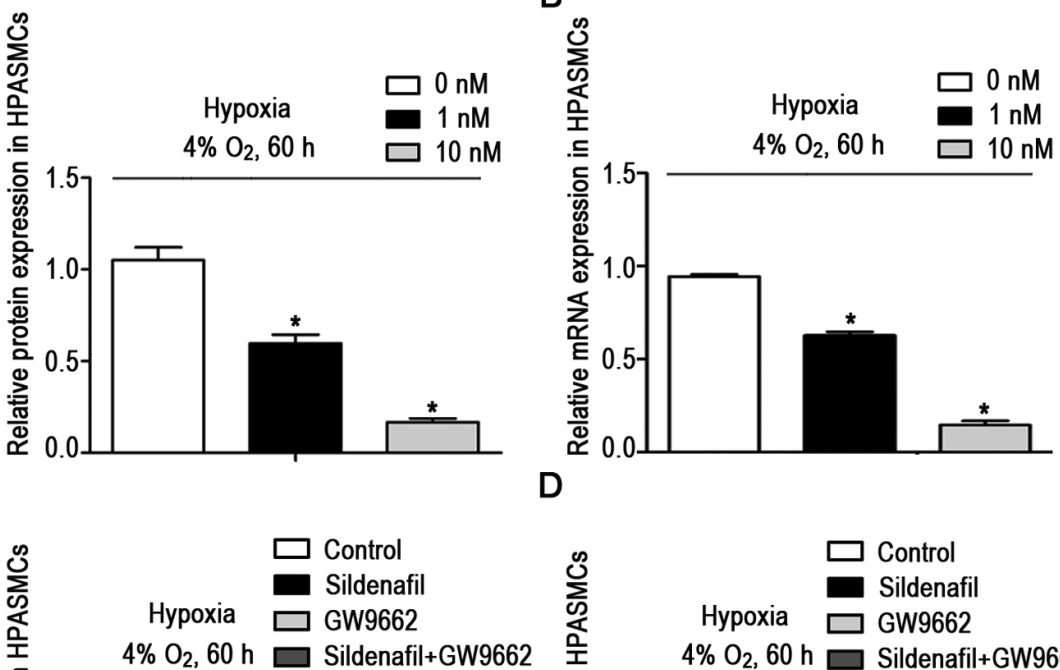

$55 \mathrm{kDa}$

$75 \mathrm{kDa}$

$100 \mathrm{kDa}$

$359 \mathrm{kDa}$

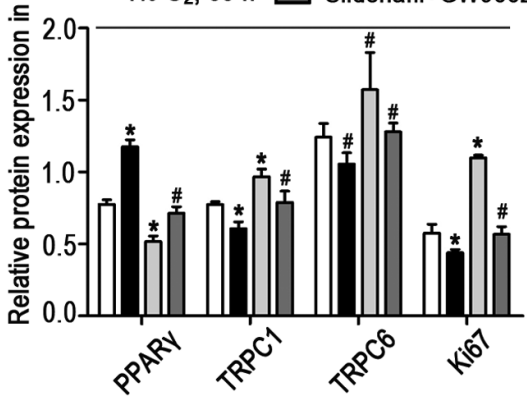

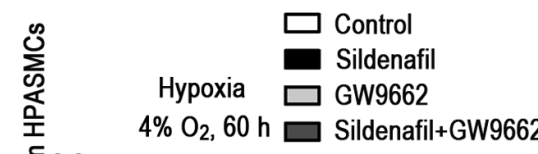

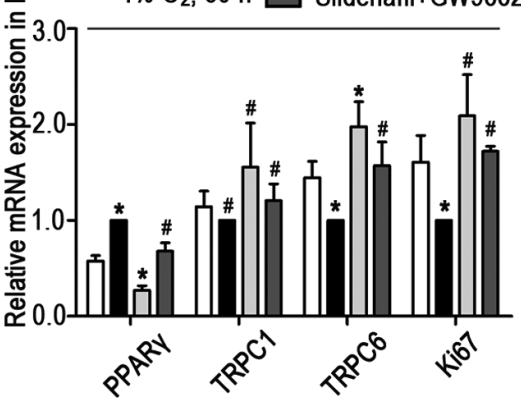

Figure 6. A PPAR $\gamma$ inhibitor (GW9662) inhibited the sildenafil-induced downregulation of TRPC and Ki67 protein expression in HPASMCs under hypoxic conditions. (A) Western blot and (B) RT-qPCR analysis of the inhibitory effects of different concentrations of a PPAR $\gamma$ inhibitor (GW9662) on PPAR $\gamma$ protein expression in HPASMCs under hypoxic conditions. Cells were treated with either 0, 1 or $10 \mathrm{nM}$ GW9662. (C) Western blot and (D) RT-qPCR analysis of the inhibitory effect of a PPAR $\gamma$ inhibitor (GW9662) on the sildenafil-induced downregulation of TRPC and Ki67 protein expression in HPASMCs under hypoxic conditions. There were four groups: i) The hypoxic control group $\left(60 \mathrm{~h}, 4 \% \mathrm{O}_{2}\right)$, ii) the hypoxia + sildenafil group (60 h, $\left.4 \% \mathrm{O} 2\right)$, iii) the hypoxia $+\mathrm{GW} 9662$ group $\left(60 \mathrm{~h}, 4 \% \mathrm{O}_{2}, 10 \mathrm{nM}\right)$, and (iv) the hypoxia + sildenafil + GW9662 group $\left(60 \mathrm{~h}, 4 \% \mathrm{O}_{2}, 10 \mathrm{nM}\right)$. Data are presented as the mean \pm standard deviation of three repeats. ${ }^{*} \mathrm{P}<0.05$ vs. control, ${ }^{\#} \mathrm{P}>0.05$ vs. control. PPAR $\gamma$, peroxisome proliferator-activated receptor $\gamma$; HPASMC, human pulmonary artery smooth muscle cell; TRPC, transient receptor potential canonical; RT-qPCR, reverse transcription-quantitative PCR.

iv) the hypoxia + sildenafil + GW9662 group $(n=3)$. The results showed that sildenafil increased the expression of PPAR $\gamma$ and decreased the expression of TRPC1, TRPC6 and Ki67 under hypoxic conditions $\left(4 \% \mathrm{O}_{2}, 60 \mathrm{~h}\right.$; Fig. $6 \mathrm{C}$ and D). However, when sildenafil and GW9662 were used simultaneously, GW9662 attenuated the upregulation of PPAR $\gamma$ and the inhibition of TRPC1, TRPC6 and Ki67 expression induced by sildenafil.

The effects of sildenafil and PPAR $\gamma$ siRNA on the expression of TRPCs and Ki67 in cultured HPASMCs under hypoxic conditions were further investigated. HPASMCs were transfected with siRNA (Fig. 7A and B), the expression levels of PPAR $\gamma$ decreased significantly, indicating that PPAR $\gamma$ had been successfully knocked down. As illustrated in Fig. 7C and D, the expression levels of TRPC1, TRPC6 and Ki67 were significantly increased after transfection with PPAR $\gamma$ siRNA, but sildenafil did not notably downregulate the expression levels of TRPC1 and TRPC6.

\section{Discussion}

PPHN is the most common severe pulmonary vascular disease in the NICU, with an incidence of $2 / 1,000$ live births (27) and a mortality rate of $4-33 \%$ in US centers (1). In addition to a continuously increased pulmonary artery pressure, excessive remodeling of the distal pulmonary arterioles (including thickening of the pulmonary vascular wall and obstruction of small blood vessels) and right ventricular hypertrophy are major features of this disease.

Despite significant improvements in health care, $\sim 1.9 \%$ of newborns are exposed to intermittent or chronic hypoxia during the perinatal period and are at risk of developing PPHN. Compared with adult pulmonary vessels, neonatal pulmonary vessels are more vulnerable to hypoxic injury. In this study, hypoxic conditions were used to induce pulmonary hypertension in neonatal rats (28).

There are several animal models used for the study of neonatal pulmonary hypertension. For example, in fetal lambs, contraction of the ductus arteriosus can produce fetal and neonatal pulmonary hypertension. After delivery, the lambs have persistent hypoxemia and increased pulmonary vascular resistance, and thus can be used as an important experimental model for human infant PPHN. This model of PPHN is associated with significant pulmonary vascular remodeling and elevated levels of reactive oxygen species in the lungs and pulmonary arteries (29). Hyperoxia exposure can also lead to vascular remodeling and pulmonary hypertension, so this 
A

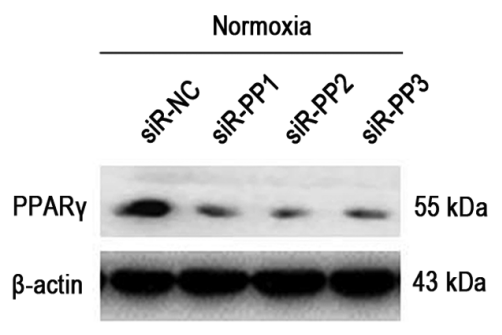

C

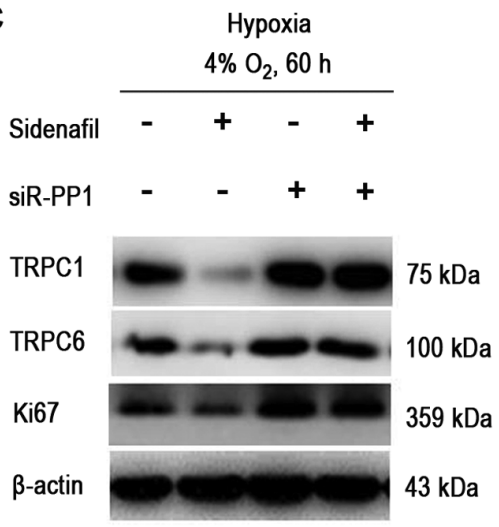

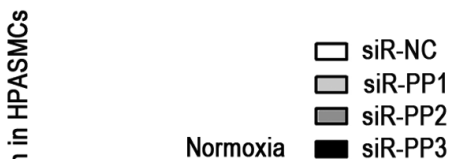
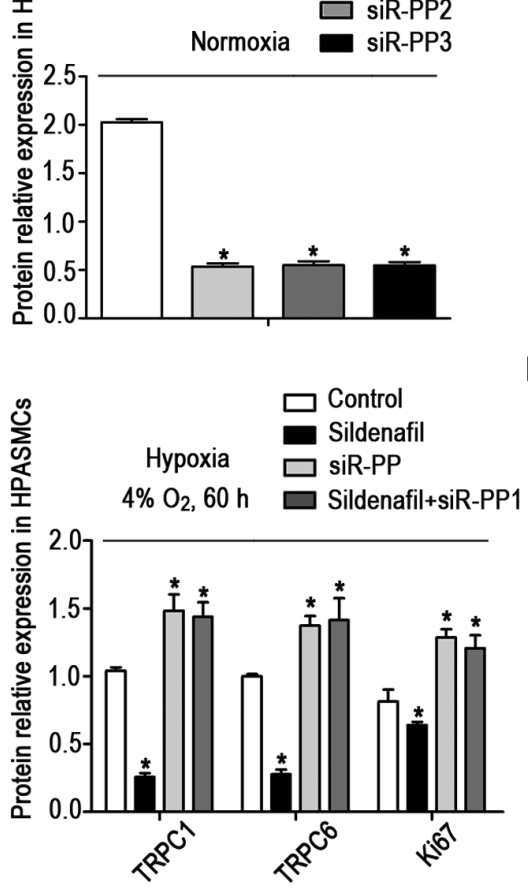

B

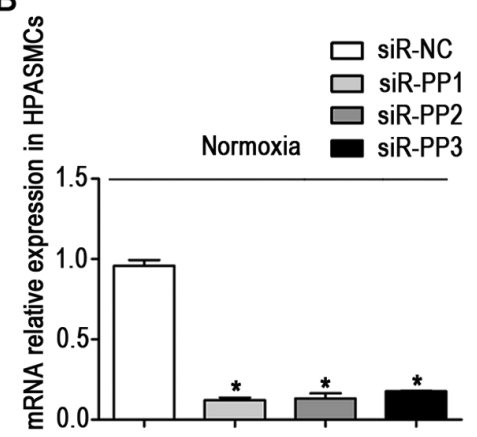

D

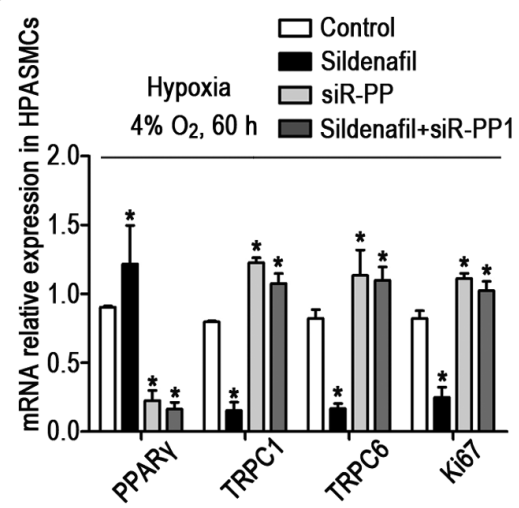

Figure 7. si-PPAR $\gamma$ reversed the sildenafil-induced downregulation of TRPC and Ki67 expression under hypoxic conditions. (A) Western blot and (B) RT-qPCR analysis of the downregulation of PPAR $\gamma$ protein expression in HPASMCs transfected with si-PPAR $\gamma$ under normoxic conditions. There were four groups: si-NC, siR-PP1, siR-PP2 and siR-PP3. (C) Western blot and (D) RT-qPCR analysis of the reversal of the sildenafil-induced downregulation of TRPC and Ki67 protein expression in HPASMCs induced by PPAR $\gamma$ siRNA under hypoxic conditions. There were four groups: i) The hypoxic control group (60 h, $4 \%$ O $)_{2}$, ii) the hypoxia + sildenafil group $\left(60 \mathrm{~h}, 4 \% \mathrm{O}_{2}\right)$, iii) the hypoxia + siR-PP1 group $\left(60 \mathrm{~h}, 4 \% \mathrm{O}_{2}\right)$, and iv) the hypoxia + sildenafil + siR-PP1 group. Data are presented as the mean \pm standard deviation of three repeats. ${ }^{*} \mathrm{P}<0.05$ vs. control. PPAR $\gamma$, peroxisome proliferator-activated receptor $\gamma$; HPASMC, human pulmonary artery smooth muscle cell; siRNA, small interfering RNA; NC, negative control; RT-qPCR, reverse transcription-quantitative PCR.

model is often used to study bronchopulmonary dysplasia. Hyperoxia exposure interferes with the signaling pathways required for lung development and repair in premature and newborn mice and interrupts alveolar formation and pulmonary angiogenesis (30).

At present, PPHN treatment is based on a comprehensive strategy involving inhaled nitric oxide (iNO); high-frequency ventilation; and application of pulmonary dilation-inducing vascular drugs, including prostaglandins, endothelin receptor antagonists and phosphodiesterase 5 inhibitors (such as sildenafil and tadalafil) (27).

At present, the phosphodiesterase 5 inhibitor sildenafil, a selective and potent vasodilator, has been developed as an alternative therapy or as an adjuvant for PPHN treatment with iNO, and is also the most widely used pulmonary vasoactive drugs in the clinic (10). Clinical studies have shown that sildenafil significantly reduces mortality and that it is more effective than placebo in improving oxygenation $(1,9)$. In previous animal studies, large experimental animals, such as newborn sheep and newborn pigs, have been used (31-34). Sildenafil has rarely been used in neonatal rat models of pulmonary hypertension to the best of our knowledge, but the use of such small animals can reduce the cost and increase the repeatability of the experiments.

The pathogenesis of PPHN is complex and still not fully understood. Currently, proliferation and migration disorders of PASMCs are suggested to be the main causes of the abnormal excessive remodeling of distal pulmonary arterioles that occurs during the pathogenesis of pulmonary hypertension (35). $\alpha$-SMA is a commonly used vascular smooth muscle cell marker in part because it is the first protein expressed in smooth muscle cell differentiation during development and because it shows specificity for smooth muscle cells (35). In addition, $\alpha$-SMA is required for force contraction in fully differentiated smooth muscle cells, and is the most abundant protein in differentiated smooth muscle cells, accounting for $40 \%$ of total cellular proteins (35). Therefore, $\alpha$-SMA-labeled pulmonary vascular smooth muscle cells were used in the present study. To identify the effects of sildenafil on PPAR $\gamma$, TRPCs and Ki67 in the smooth muscle cells of distal pulmonary arterioles, $\alpha$-SMA was double-stained with PPAR $\gamma$, TRPCs and Ki67.

An increasing number of studies have shown that PPAR $\gamma$ plays an important role in the pathogenesis of pulmonary hypertension (36). PPAR $\gamma$, a member of one of three related nuclear receptor superfamilies (PPAR $\alpha, \operatorname{PPAR} \gamma$ and PPAR $\beta / \delta$ ), is a ligand-activated transcription factor (15). Research has shown that PPAR $\gamma$ plays important roles in glucose homeostasis and fatty acid metabolism and that it can also attenuate vascular dysfunction (37-39). In addition to being highly expressed in adipocytes, cardiomyocytes, macrophages and renal podocytes (14), PPAR $\gamma$ is highly expressed in cell types in the pulmonary vascular wall, including vascular endothelial cells and smooth muscle cells $(15,35,40)$. In the present study, the expression levels of PPAR $\gamma$ were significantly decreased in 
the distal pulmonary arterioles and lung tissues of the PPHN group, consistent with observations in the literature. Studies have shown that PPAR $\gamma$ can inhibit the proliferation and migration of smooth muscle cells by blocking the expression of platelet-derived growth factor. In addition, PPAR $\gamma$ induces smooth muscle cell apoptosis by mediating phosphorylation of the retinoblastoma gene and by increasing the expression of the proapoptotic protein Gadd45 (5). Treatment with the PPAR $\gamma$ agonists rosiglitazone (37) and pioglitazone (2) attenuated the progression of hypoxia-induced pulmonary hypertension and pulmonary vascular remodeling.

Sildenafil can promote fat formation by increasing the expression of PPAR $\gamma$ in adipocytes. PPAR $\gamma$ also mediates the protective effect of sildenafil against acute kidney injury (17) induced by ischemia-reperfusion in rats and Adriamycin-induced nephropathy (14). In the present study, the application of sildenafil significantly inhibited the decreases in PPAR $\gamma$ expression in distal PASMCs and lung tissue caused by chronic hypoxia, producing an effect similar to that of PPAR $\gamma$ agonists; thus, sildenafil may reduce hypoxia-induced pulmonary artery pressure changes and pulmonary vascular remodeling by activating PPAR $\gamma$ expression. The precise mechanism by which sildenafil upregulates PPAR $\gamma$ remains entirely unknown. Sonneveld et al (14) proposed a mechanism in which sildenafil-induced increases in cGMP levels lead to further activation of PKG-1 and then PPAR $\gamma$.

Increased free calcium concentrations in PASMCs are major contributors to pulmonary vasoconstriction and can stimulate the proliferation and migration of PASMCs, all of which can cause pulmonary vascular remodeling $(18,41)$. There are three main $\mathrm{Ca}^{2+}$ channels on PASMCs: L-type voltage-dependent $\mathrm{Ca}^{2+}$ channels, ROCCs and calcium pool-related SOCCs. Amongst them, ROCCs and SOCCs play an important role in the pathogenesis of pulmonary hypertension (5). The typical TRPC gene family members are known to form the molecular basis for SOCCs and ROCCs in PASMCs, and it has previously been shown that chronic hypoxia selectively upregulates the expression of TRPC1 and TRPC6 in PASMCs (18). In the present study, TRPC1 and TRPC6 expression was significantly increased in the distal PASMCs of the PPHN group. The high expression levels of TRPC1 and TRPC6 were significantly attenuated after the application of sildenafil, indicating that sildenafil may also reduce the intracellular $\mathrm{Ca}^{2+}$ concentration, reduce pulmonary vasoconstriction, and inhibit pulmonary vascular remodeling by reducing the expression of TRPC1 and TRPC6. These changes can improve pulmonary hypertension.

Studies have shown that PPAR $\gamma$ can inhibit the expression of SOCE channels and TRPCs in PASMCs by inhibiting caveolin-1 (19). These results indicate that PPAR $\gamma$ acts as an upstream signal of TRPCs, and affects the proliferation and migration of PASMCs through TRPCs. In addition, Sonneveld et al (14) found that treatment with PPAR $\gamma$ agonists in vitro and in vivo downregulated the expression levels of TRPC6, reduced podocyte damage caused by Adriamycin and improved the associated proteinuria. Further chromatin immunoprecipitation analysis showed that PPAR $\gamma$ can bind to the TRPC6 promoter and regulate the expression and activity of TRPC6 through a direct mechanism of action (14).
In conclusion, the present study demonstrated that sildenafil may attenuate pulmonary vasoconstriction by activating PPAR $\gamma$ and downregulating TRPC1 and TRPC6, thereby reducing pulmonary hypertension and inhibiting the thickening of the distal pulmonary arteriole wall, in neonatal rats exposed to hypoxia. However, further studies are needed to validate the roles of PPAR $\gamma$, TRPC1 and TRPC6 in pulmonary hypertension in neonatal rats.

\section{Acknowledgements}

Not applicable.

\section{Funding}

No funding was received.

\section{Availability of data and materials}

The datasets used and/or analyzed during the present study are available from the corresponding author on reasonable request.

\section{Authors' contributions}

WH performed the experiments and participated in the design, statistics, drafting and revising of the manuscript. NL, XT and YD performed the experiments and analyzed the data. All authors read and approved the final manuscript. WH and NL confirm the authenticity of all the raw data.

\section{Ethics approval and consent to participate}

The animal experiments performed in the present study were approved by the institutional review board of Shengjing Hospital of China Medical University.

\section{Patient consent for publication}

Not applicable

\section{Competing interests}

The authors declare that they have no competing interests.

\section{References}

1. Kelly LE, Ohlsson A and Shah PS: Sildenafil for pulmonary hypertension in neonates. Cochrane Database Syst Rev 8: CD005494, 2017.

2. Behringer A, Trappiel M, Berghausen EM, Ten Freyhaus H, Wellnhofer E, Odenthal M, Blaschke F, Er F, Gassanov N, Rosenkranz S, et al: Pioglitazone alleviates cardiac and vascular remodelling and improves survival in monocrotaline induced pulmonary arterial hypertension. Naunyn Schmiedebergs Arch Pharmacol 389: 369-379, 2016.

3. Tajsic T and Morrell NW: Smooth muscle cell hypertrophy, proliferation, migration and apoptosis in pulmonary hypertension. Compr Physiol 1: 295-317, 2011.

4. Zhang Y, Cui Y, Deng W, Wang H, Qin W, Huang C, Li C, Zhang J, Guo Y, Wu D, et al: Isoquercitrin protects against pulmonary hypertension via inhibiting PASMCs proliferation. Clin Exp Pharmacol Physiol 44: 362-370, 2017.

5. Afdal P and AbdelMassih AF: Is pulmonary vascular disease reversible with PPAR $\gamma$ agonists? Microcirculation 25: e12444, 2018. 
6. Kahveci H, Yilmaz O, Avsar UZ, Ciftel M, Kilic O, Laloglu F and Ozturk K: Oral sildenafil and inhaled iloprost in the treatment of pulmonary hypertension of the newborn. Pediatr Pulmonol 49: $1205-1213,2014$

7. Kraemer U, Cochius-den Otter S, Snoek KG and Tibboel D: Pharmacodynamic considerations in the treatment of pulmonary hypertension in infants: Challenges and future perspectives Expert Opin Drug Metab Toxicol 12: 1-19, 2016

8. Yamamura A, Fujitomi E, Ohara N, Tsukamoto K, Sato M and Yamamura H: Tadalafil induces antiproliferation, apoptosis, and phosphodiesterase type 5 downregulation in idiopathic pulmonary arterial hypertension in vitro. Eur J Pharmacol 810 44-50, 2017.

9. Barst RJ, Beghetti M, Pulido T, Layton G, Konourina I, Zhang M and Ivy DD; STARTS-2 Investigators: STARTS-2: Long-term survival with oral sildenafil monotherapy in treatment-naive pediatric pulmonary arterial hypertension. Circulation 129: 1914-1923, 2014.

10. Iacovidou N, Syggelou A, Fanos V and Xanthos T: The use of sildenafil in the treatment of persistent pulmonary hypertension of the newborn: A review of the literature. Curr Pharm Des 18 3034-3045, 2012.

11. Wang RC, Jiang FM, Zheng QL, Li CT, Peng XY, He CY, Luo J and Liang ZA: Efficacy and safety of sildenafil treatment in pulmonary arterial hypertension: A systematic review. Respir Med 108: 531-537, 2014

12. Francis SH, Busch JL, Corbin JD and Sibley D: cGMP-dependent protein kinases and cGMP phosphodiesterases in nitric oxide and cGMP action. Pharmacol Rev 62: 525-563, 2010.

13. Lu W, Ran P, Zhang D, Peng G, Li B, Zhong N and Wang J: Sildenafil inhibits chronically hypoxic upregulation of canonical transient receptor potential expression in rat pulmonary arteria smooth muscle. Am J Physiol Cell Physiol 298: C114-C123, 2010.

14. Sonneveld R, Hoenderop JG, Isidori AM,Henique C, Dijkman HB, Berden JH, Tharaux PL, van der Vlag J and Nijenhuis T: Sildenafil prevents podocyte injury via PPAR- $\gamma$-mediated TRPC6 inhibition. J Am Soc Nephrol 28: 1491-1505, 2017.

15. Chandra M, Miriyala S and Panchatcharam M: PPAR $\gamma$ and its role in cardiovascular diseases. PPAR Res 2017: 6404638, 2017.

16. Martinho S, Adão R, Leite-Moreira AF and Brás-Silva C: Persistent pulmonary hypertension of the newborn: Pathophysiological mechanisms and novel therapeutic approaches. Front Pediatr 8: 342, 2020

17. Mohey V, Singh M, Puri N, Kaur T, Pathak D and Singh AP: Sildenafil obviates ischemia-reperfusion injury-induced acute kidney injury through peroxisome proliferator-activated receptor $\gamma$ agonism in rats. J Surg Res 201: 69-75, 2016.

18. Xia Y, Yang XR, Fu Z, Paudel O, Abramowitz J, Birnbaumer L and Sham JS: Classical transient receptor potential 1 and 6 contribute to hypoxic pulmonary hypertension through differential regulation of pulmonary vascular functions. Hypertension 63 173-180, 2014

19. Yang K, Lu W, Jiang Q, Yun X, Zhao M, Jiang H and Wang J: Peroxisome proliferator-activated receptor $\gamma$-mediated inhibition on hypoxia-triggered store-operated calcium entry. A Caveolin-1-dependent mechanism. Am J Respir Cell Mol Biol 53: 882-892, 2015

20. Du Y, Fu J, Yao L, Qiao L, Liu N, Xing Y and Xue X: Altered expression of PPAR $\gamma$ and TRPC in neonatal rats with persistent pulmonary hypertension. Mol Med Rep 16: 1117-1124, 2017.

21. Xu YP, Zhu JJ, Cheng F, Jiang KW, Gu WZ, Shen Z, Wu YD Liang L and Du LZ: Ghrelin ameliorates hypoxia-induced pulmonary hypertension via phospho-GSK3 $\beta / \beta$-catenin signaling in neonatal rats. J Mol Endocrinol 47: 33-43, 2011.

22. Du Y, Fu J, Yao L, Zhang D, Liu N and Xue X: Effects of FHL1 and P21 on hypoxia-induced pulmonary vascular remodeling in neonatal rats. Exp Ther Med 14: 4245-4253, 2017.

23. Jasińska-Stroschein M, Owczarek J, Łuczak $A$ and Orszulak-Michalak D: The beneficial impact of fasudil and sildenafil on monocrotaline-induced pulmonary hypertension in rats: A hemodynamic and biochemical study. Pharmacology 91 178-184, 2013

24. Livak KJ and Schmittgen TD: Analysis of relative gene expression data using real-time quantitative PCR and the 2(-Delta Delta C(T)) Method. Methods 25: 402-408, 2001

25. Li Y, Liu G, Cai D, Pan B, Lin Y, Li X, Li S, Zhu L, Liao X and Wang $\mathrm{H}$ : $\mathrm{H} 2 \mathrm{~S}$ inhibition of chemical hypoxia-induced proliferation of HPASMCs is mediated by the upregulation of COX-2/PGI2. Int J Mol Med 33: 359-366, 2014.
26. Lin C, Li X, Luo Q, Yang H, Li L, Zhou Q, Li Y, Tang H and Wu L: RELM- $\beta$ promotes human pulmonary artery smooth muscle cell proliferation via FAK-stimulated surviving. Exp Cell Res 351: 43-50, 2017

27. Hilgendorff A, Apitz C, Bonnet D and Hansmann G: Pulmonary hypertension associated with acute or chronic lung diseases in the preterm and term neonate and infant. The European Paediatric Pulmonary Vascular Disease Network, endorsed by ISHLT and DGPK. Heart 102 (Suppl 2): ii49-ii56, 2016.

28. Xu YP, He Q, Shen Z, Shu XL, Wang CH, Zhu JJ, Shi LP and Du LZ: miR-126a-5p is involved in the hypoxia-induced endothelial-to-mesenchymal transition of neonatal pulmonary hypertension. Hypertens Res 40: 552-561, 2017.

29. Gong J, Feng Z, Peterson AL, Carr JF, Vang A, Braza J, Choudhary G, Dennery PA and Yao H: Endothelial to mesenchymal transition during neonatal hyperoxia-induced pulmonary hypertension. J Pathol 252: 411-422, 2020.

30. Menon RT, Shrestha AK, Reynolds CL, Barrios R, Caron KM and Shivanna B: Adrenomedullin is necessary to resolve hyperoxia-induced experimental bronchopulmonary dysplasia and pulmonary hypertension in mice. Am J Pathol 190: 711-722, 2020.

31. Makker K, Afolayan AJ, Teng RJ and Konduri GG: Altered hypoxia-inducible factor- $1 \alpha$ (HIF-1 $\alpha$ ) signaling contributes to impaired angiogenesis in fetal lambs with persistent pulmonary hypertension of the newborn (PPHN). Physiol Rep 7: e13986, 2019.

32. Cohen SS, Powers BR, Lerch-Gaggl A, Teng RJ and Konduri GG: Impaired cerebral angiogenesis in the fetal lamb model of persistent pulmonary hypertension. Int J Dev Neurosci 38: 113-118, 2014.

33. Amer R, Elsayed YN, Graham MR, Sikarwar AS, Hinton M and Dakshinamurti S: Effect of vasopressin on a porcine model of persistent pulmonary hypertension of the newborn. Pediatr Pulmonol 54: 319-332, 2019.

34. Blasina F, Vaamonde L, Silvera F, Solla G, Abin-Carriquiry JA, Gutiérrez C, Beltramo P, Garcia-Gabay I and Martell M: Efficacy and safety of a novel nitric oxide generator for the treatment of neonatal pulmonary hypertension: Experimental and clinical studies. Pulm Pharmacol Ther 54: 68-76, 2019.

35. Fernandez RA, Wan J, Song S, Smith KA, Gu Y, Tauseef M, Tang H, Makino A, Mehta D and Yuan JX: Upregulated expression of STIM2, TRPC6, and Orai2 contributes to the transition of pulmonary arterial smooth muscle cells from a contractile to proliferative phenotype. Am J Physiol Cell Physiol 308: C581-C593, 2015.

36. Tseng V, Sutliff RL and Hart CM: Redox biology of peroxisome proliferator-activated receptor- $\gamma$ in pulmonary hypertension. Antioxid Redox Signal 31: 874-897, 2019.

37. Grygiel-Górniak B: Peroxisome proliferator-activated receptors and their ligands: Nutritional and clinical implications - a review. Nutr J 13: 17, 2014.

38. Wang L, Waltenberger B, Pferschy-Wenzig EM, Blunder M, Liu X, Malainer C, Blazevic T, Schwaiger S, Rollinger JM, Heiss $\mathrm{EH}$, et al: Natural product agonists of peroxisome proliferator-activated receptor gamma (PPAR $\gamma$ ): A review. Biochem Pharmacol 92: 73-89, 2014.

39. Ajith TA and Jayakumar TG: Peroxisome proliferator-activated receptors in cardiac energy metabolism and cardiovascular disease. Clin Exp Pharmacol Physiol 43: 649-658, 2016.

40. Wang Y, Lu W, Yang K, Wang Y, Zhang J, Jia J, Yun X, Tian L, Chen Y,Jiang Q, et al: Peroxisome proliferator-activated receptor $\gamma$ inhibits pulmonary hypertension targeting store-operated calcium entry. J Mol Med (Berl) 93: 327-342, 2015.

41. Malczyk M, Veith C, Fuchs B, Hofmann K, Storch U, Schermuly RT, Witzenrath M, Ahlbrecht K, Fecher-Trost C, Flockerzi V, et al: Classical transient receptor potential channel 1 in hypoxia-induced pulmonary hypertension. Am J Respir Crit Care Med 188: 1451-1459, 2013.

This work is licensed under a Creative Commons Attribution-NonCommercial-NoDerivatives 4.0 International (CC BY-NC-ND 4.0) License. 